\title{
Activation of the viral sensor oligoadenylate synthetase 2 (Oas2) prevents pregnancy-driven mammary cancer metastases
}

Wing-Hong Jonathan Ho

Garvan Institute of Medical Research

Andrew M. K. Law

Garvan Institute of Medical Research

Etienne Masle-Farquhar

Garvan Institute of Medical Research

Lesley E. Castillo

Garvan Institute of Medical Research

Amanda Mawson

Garvan Institute of Medical Research

Moira K. O'Bryan

The University of Melbourne School of BioSciences

Christopher C. Goodnow

Garvan Institute of Medical Research

David Gallego Ortega

University of Technology Sydney

Samantha R. Oakes

National Breast Cancer Foundation

Christopher Ormandy ( $\nabla$ c.ormandy@garvan.org.au )

Garvan Institute of Medical Research https://orcid.org/0000-0002-2504-7919

Research article

Keywords: OAS2, interferon, immunotherapy, breast, mammary, cancer

Posted Date: September 2nd, 2021

DOI: https://doi.org/10.21203/rs.3.rs-842107/v1

License: (c) (i) This work is licensed under a Creative Commons Attribution 4.0 International License.

Read Full License 
1 Activation of the viral sensor oligoadenylate synthetase 2 (Oas2) prevents pregnancy-driven mammary cancer metastases.

3

4 Wing-Hong Jonathan $\mathrm{Ho}^{1}$, Andrew M. K. Law ${ }^{1}$, Etienne Masle-Farquhar ${ }^{1}$, Lesley E.

5 Castillo $^{1}$, Amanda Mawson ${ }^{1}$, Moira K. O’Bryan², Christopher C. Goodnow ${ }^{1}$, David

6 Gallego-Ortega ${ }^{1,3}$, Samantha R. Oakes ${ }^{1,4,5}$ and Christopher J. Ormandy ${ }^{1,4,6}$

${ }^{1}$ Garvan Institute of Medical Research, 384 Victoria Street Darlinghurst Sydney, NSW, 2010, Australia, and St. Vincent's Clinical School, St. Vincent's Hospital, UNSW Sydney, Australia.

2 The School of BioSciences and Bio21 Institute, Faculty of Science, The University of Melbourne, Parkville, Melbourne, Vic. 3010, Australia.

${ }^{3}$ Current address, School of Biomedical Engineering. Faculty of Engineering and Information Technology. University of Technology Sydney, 81 Broadway, Ultimo Sydney, NSW, 2007, Australia.

${ }^{4}$ Joint senior authors.

${ }^{5}$ Current address, National Breast Cancer Foundation, 9/10 Barrack Street, Sydney NSW, 2000, Australia.

${ }^{6}$ To whom correspondence should be addressed.

Running title; OAS2 activation prevents metastases.

Keywords; OAS2, interferon, immunotherapy, breast, mammary, cancer.

Wing-Hong Jonathan Ho j.ho@garvan.org.au

Andrew Law a.law@garvan.org.au

Etienne Masle-Farquhar e.masle-farquhar@garvan.org.au (iD) https://orcid.org/0000$\underline{0001-9355-8027}$

Lesley Castillo CastilloLesley@prahs.com

Amanda Mawson a.mawson@garvan.org.au

Moira K. O’Bryan moira.obryan@unimelb.edu.au (iD http://orcid.org/0000-0001$\underline{7298-4940}$

Christopher C. Goodnow c.goodnow@garvan.org.au iD http://orcid.org/0000-0001$\underline{\text { 5296-6155 }}$

David Gallego Ortega David.GallegoOrtega@uts.edu.au iDhttps://orcid.org/0000$\underline{\text { 0002-2347-7835 }}$

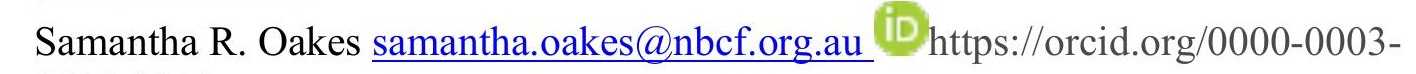
1838-2310

Christopher J. Ormandy c.ormandy@garvan.org.au iD https://orcid.org/0000-00022504-7919 


\section{Abstract}

43 Background. The interferon response can influence the primary and metastatic activity 44 of breast cancers and can interact with checkpoint immunotherapy to modulate its 45 effects. Using N-ethyl-N-nitrosourea mutagenesis we found a mouse with an activating 46 mutation in oligoadenylate synthetase 2 (Oas2), a sensor of viral double stranded RNA, 47 that resulted in an interferon response and prevented lactation in otherwise healthy 48 mice.

49 Methods. To determine if activation of Oas 2 could alter the course of mammary cancer 50 we combined the Oas 2 mutation with the MMTV-PyMT oncogene model of breast 51 cancer and examined disease progression and the effects of checkpoint immunotherapy 52 using Kaplan-Meier survival analysis with immunohistochemistry and flow cytometry. 53 Results. Oas 2 mutation prevented pregnancy from increasing metastases to lung. 54 Checkpoint immunotherapy with antibodies against programmed death-ligand 1 (PD55 L1) was more effective when the Oas2 mutation was present.

56 Conclusions. These data establish OAS2 as a therapeutic target for agents designed to 57 reduce metastases and increase the effectiveness of checkpoint immunotherapy in cases 58 of pregnancy-associated breast cancer and outside of pregnancy in cases showing the 59 lactation and involution-mimicry phenotypes. 


\section{Background.}

62

The interferon response can influence the primary and metastatic activity of breast cancers ${ }^{1}$, and can interact with checkpoint immunotherapy to modulate its effects ${ }^{2}$. Although systemic interferon delivery for cancer produced responses in tumors, it was limited by severe adverse events and has been superseded by newer therapies ${ }^{3}$. To circumvent some of these challenges intratumor injection of agents that induce an interferon response are currently being trialled in a large number of cancer settings and among these agents are derivatives of polyinosinic-polycytidylic acid (polyIC) ${ }^{4}$. In mice polyIC greatly improved the ability of anti PD-L1 therapy to clear or reduce melanomas and cancers of the lung and colon, and this effect was dependent on type 1 interferons ${ }^{5}$.

PolyIC mimics viral double-stranded RNA and activates a diverse range of pathogen recognition receptors including the oligoadenylate synthetase (OAS) family, retinoic acid induced gene 1 (RIG1)-like family and toll-like receptors. The OAS family of proteins are often overlooked as potent inducers of the interferon response. They are pathogen recognition receptors that bind double-stranded RNA in the cytoplasm, a key pathogen-associated molecular-pattern that is displayed during viral replication ${ }^{6}$. These proteins respond by synthesizing $2^{\prime}-5^{\prime}$-linked RNA from ATP without a template ${ }^{7}$. This in turn binds to and activates latent ribonuclease (RNaseL), causing it to degrade viral RNA and host ribosomal RNA, so disrupting the viral life cycle. Activation of OAS-RNaseL also promotes apoptosis and provokes a robust interferon response, both via poorly understood mechanisms that involve additional detection of RNaseLdegraded RNA by the RIG1-like pathogen recognition receptors and interaction with the mitochondria ${ }^{8}$.

Activation of OAS2-RNaseL was predicted to alter outcomes in virally-induced cancers, and an association with RNaseL allelic variation and the risk of human papilloma virus-driven cancers of the cervix and head was demonstrated. Unexpectedly this study also found an association with cancers that do not show a strong viral etiology such as breast ${ }^{9}$. Activation of OAS-RNaseL may occur naturally in cancers, driven by the recognition of double-stranded RNA species produced from viral sequences integrated in the genome. These sequences are usually silenced by methylation but are transcribed de novo as a result of the general demethylation of the genome that occurs in cancer cells. This was demonstrated by the finding that cells deficient in the OAS- 
95 RNaseL pathway were highly resistant to the cytotoxicity of 5-azacytidine, a drug that demethylates the genome. Cells were made resistant to 5-azacytidine via inhibition of RNaseL ${ }^{10}$.

Other cancer studies found that allelic variation in RNaseL was observed to be associated with increased risk of prostate cancer and the increased risk of higher tumor grade, together with an increased level of inflammation markers ${ }^{11,12}$. Allelic variation of RNaseL may modify the risk of breast cancer in patients carrying high risk mutations 13. The inherited RNaseL alleles responsible for this are proposed to reduce RNaseL activity, and this proposition is supported by observations in lung cancer cells, which increased the levels of the RNaseL inhibitor RL1 to suppress RNaseL-driven apoptosis, with mitochondrial-mediated apoptosis restored by interferon gamma ${ }^{14}$.

Our laboratories conducted an N-ethyl-N-nitrosourea mutagenesis project in mice to find new genes driving mammary gland development and function, with the intent of also identifying new genes involved in mammary cancer initiation and metastasis. We discovered a dominant mutation in Oas2, (referred to as MT, wild type Oas 2 referred to as WT) causing a non-conservative amino acid change that resulted in

111 failed lactation despite normal mammary development during pregnancy. These mice 112 were otherwise completely normal ${ }^{15}$. We observed a robust interferon response 113 associated with apoptosis in the mammary glands of our MT mice. When MT was 114 expressed in human breast cancer cells we found that the interferon response depended 115 on the presence of RNaseL and interferon regulatory factor 7 (IRF7), the key effector 116 molecules at the proximal and distal ends of the OAS-RNaseL signaling pathway ${ }^{15}$. 117 This was the first observation of a regulatory pathway linking activation of viral 118 recognition to the control of lactation. The Oas 2 mutant mouse provides a defined and 119 single molecular event that induces an interferon response, with pathological activity 120 only in the mammary gland at the onset of lactation.

To determine if activation of OAS-RNaseL can alter the initiation or 122 progression of mammary cancer, and the interaction with checkpoint immunotherapy, 123 we combined the Oas 2 mutation with expression of the polyoma middle $\mathrm{T}$ oncogene 124 (PyMT) driven by the mouse mammary tumor virus promoter $(M M T V)^{16}$. This $M M T V$ 125 PyMT model is the most widely used mouse model of breast cancer. PyMT protein ${ }^{17}$ 126 acts as a scaffold promoting persistent signaling via binding of SRC family kinases, 127 PI3K, SHC, 14-3-3, PLC-gamma and TAZ. It causes early and multifocal onset of 128 estrogen receptor positive hyperplasia that rapidly progresses through a series of well- 
129 defined lesions to estrogen receptor negative invasive carcinoma of the luminal 130 molecular subtype ${ }^{18}$. The model is weakly sensitive ${ }^{19}$ or refractory ${ }^{20}$ to PD-L1 or PD1311 as monotherapy. Metastasis to lung is frequent and strongly dependent on innate 132 immune cells previously characterized, as macrophages ${ }^{21,} 22$ or myeloid derived 133 suppressor cells (MDSC) ${ }^{23}$ of monocytic (G-MDSC) or neutrophil (PMN-MDSC) 134 origin, and now thought of as pathologically activated monocytes and neutrophils ${ }^{24}$. 135 
138 Mice. The Oas2 colony ${ }^{15}$, on an inbred FVBN background was crossed with the 139 polyoma middle T antigen mouse (MMTV-PyMT) also on an FVBN background, a kind 140 gift from Dr. William Muller ${ }^{16}$. The colony was then maintained by breeding 141 compound heterozygous males (MT Oas2/WT Oas2 / MMTV-PyMT/non transgenic) 142 with WT Oas2/WT Oas2 and non-transgenic FVBN females. All animals were housed 143 with food and water ad libitum with a 12 -h day/night cycle at $22^{\circ} \mathrm{C}$ and $80 \%$ relative 144 humidity.

145 Timed Mating. One or two 7-9 weeks old females were housed with single males 146 overnight and monitored daily for a vaginal plug, and pregnancy was confirmed by 147 weight gain. Females were single housed for parturition and pups culled at birth. 148 Mammary gland tumors were measured with callipers throughout pregnancy and the 149 post-partum period. Tumor volume $\left(\mathrm{mm}^{3}\right)$ was calculated as (minimum 150 measurement $\left.{ }^{2}\right) *($ maximum measurement $) / 2$. Mice were euthanized at specified 151 endpoints, via anesthesia $\left(5 \%\right.$ isoflurane, $\left.1 \mathrm{~L} / \mathrm{min}_{2}\right)$ followed by cervical dislocation. 152 At autopsy $4^{\text {th }}$ and combined $2^{\text {nd }} / 3^{\text {rd }}$ glands or tumor weights were recorded.

153 PDL-1 Antibody Treatment in Parous Mice. Parous mice received $10 \mu 1$ per gram body 154 weight of a solution of PDL-1 (cat BP0101) or IgG control (cat BP0090) at 1mg/ml via 155 I.P. injection for six treatments, delivered twice weekly.

156 Mammary gland whole mounts and lung collection. Mouse mammary glands, tumors 157 and lungs were harvested at specified timepoints, and fixed in $10 \%$ buffered formalin 158 for 4 hours at room temperature. Tissues were changed into $70 \%$ ethanol prior to 159 embedding in paraffin. Mammary glands were defatted in 3-4 changes of acetone 160 before being dehydrated and stained in carmine alum for whole mount photography.

161 Glands were then passed through a series of graded alcohols and embedded in paraffin 162 for sectioning and immunohistochemistry.

163 Immuno-histochemistry. Tissue sections were either stained with hematoxylin and 164 eosin for routine histochemistry or stained with antibodies to the following antigens 165 using immunohistochemistry protocols as detailed in Supplementary Table 1. For 166 analysis of lung metastasis, two or more sections at $100 \mu \mathrm{m}$ intervals were cut for 167 staining. 
Image analysis. Whole mammary gland or lung sections on glass slides were scanned in Aperio ScanScope XT at Katharina Gaus Light Microscopy Facility, and Garvan Microscope Facility, Sydney, Australia, and analyzed by QuPath ${ }^{25}$. A set of multiple reference images was used to train the DAB pixel detection algorithm. Quantification of phospho-Stat positive nuclei used the positive cell detection QuPath algorithm. Regions contain positive 3,3'-diaminobenzidine (DAB), hematoxylin or no-stain were classified by batch processing and reported as total tissue area $\left(\mu \mathrm{m}^{2}\right)$, DAB-stained area $\left(\mu \mathrm{m}^{2}\right)$, non-DAB-stained area $\left(\mu \mathrm{m}^{2}\right)$ and non-stained area $\left(\mu \mathrm{m}^{2}\right)$. DAB stain area percentage without lumen non-stained area was calculated as;

PYMT stain area percentage with non - stained area

$=\left(\frac{\text { PYMT stain area }}{\text { PYMT stain area }+ \text { non }- \text { PYMT stain area }}\right) * 100$

Kaplan-Meier survival analysis, graph drawing and statistical tests were performed in GraphPad Prism 8.0.2. Strong evidence against the observation being made by chance was accepted at the $90 \%$ level.

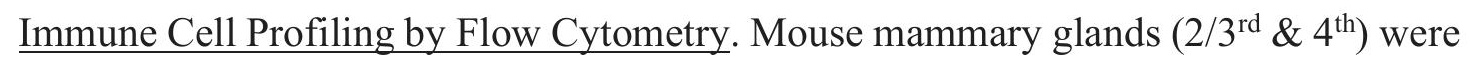
crudely macerated and cells disassociated in $1 \%$ hyaluronidase, $37^{\circ} \mathrm{C}$ shaking, $20 \mathrm{~min}$. Digestion was neutralized with $2 \%$ fetal calf serum (FCS) / phosphate buffered saline (PBS) prior to centrifugation at $1200 \mathrm{rpm}, 4^{\circ} \mathrm{C}$. Cell pellets were resuspended $(25 \mu \mathrm{g} / \mathrm{ml}$ DNAse1 in $2 \%$ FCS / PBS) and strained through $40 \mu \mathrm{m}$ mesh and the supernatant concentrated by centrifugation. Cell pellets were resuspended $0.8 \% \mathrm{NH}_{4} \mathrm{Cl}$, DNase1 $(25 \mu \mathrm{g} / \mathrm{ml})$ in PBS and incubated in $37^{\circ} \mathrm{C}$ water bath, $1 \mathrm{~min}$. Red blood cells (RBC) / DNA lysis was neutralized in $7 \mathrm{x}$ volume $2 \%$ FCS / PBS prior to centrifugation and resuspension in 2\% FCS / PBS for immune cell staining using fluorophore conjugated antibodies (refer to antibody panels in Supplementary Table 2). Mouse spleen, thymus and lymph nodes (from $4^{\text {th }}$ mammary glands) were collected separately into RPMI media (+10\% FCS) and strained through $70 \mu \mathrm{m}$ mesh directly prior to RBC / DNA lysis, cell resuspension and immune cell staining steps (as detailed above). Flow cytometry was performed using BD LSR II SORP and data exported to the FlowJo software (Tree Star Inc.) for data analysis. Routine $\mathrm{T}^{26,27}$ and innate immune cell protocols ${ }^{28}$ were followed using antibodies listed in Supplementary Table 2. 
202 Effects of pregnancy and mutation of Oas2 in the MMTV-PyMT model.

$M M T V-P y M T$ mice were made pregnant at 7-9 weeks of age and analyzed

204 between days 1-3 post-partum. Tumors arose in all glands and were generally first 205 detected by palpation in the combined $2^{\text {nd }}$ and $3^{\text {rd }}$ glands. MMTV-PYMT mice showed normal mammary ductal elongation and branching (Fig. 1A), with alveolar bud formation, but failed lobuloalveoli development (FLAD) during pregnancy. At the end of pregnancy lobuloalveoli would normally completely fill the fat pad and very few adipocytes would be seen, but in $M M T V-P y M T$ glands this does not occur. As a result

210 there were no observable differences in mammary gland development between parous

211 MT and WT mice. The failure of $M M T V-P y M T$ dams to feed their pups has been noted 212 previously ${ }^{16}$. This is due to a developmental defect and not physical obstruction of the 213 ductal network as often assumed. The mammary ductal tree showed the same 214 characteristic early lesions identified by Lin et al. ${ }^{18}$, hyperplasia, adenoma/MIN, and 215 early carcinoma, with late carcinoma dominant at animals that reached the ethical 216 endpoint. These lesions were arranged in a gradient from youngest to oldest epithelium, 217 hyperplasia to carcinoma, left to right in Fig. 1A. IHC showed that PyMT levels were 218 lowest in hyperplasia and highest in adenoma/MIN (Fig. 1B). We observed no 219 histopathological differences between MT and WT mice. Two novel features were observed in parous mice due to the accumulation of milk within the gland (Fig. 1C). In some mice engorgement with milk of adenoma/MIN produced highly distended ducts, seen on the left-hand side of the combined $2^{\text {nd }}$ and $3^{\text {rd }}$ mammary gland shown in Fig. 1B, which stained strongly for milk-associated protein (MAP). A second feature we

224 have called engorged carcinoma was characterized as misshapen and fluid-filled 225 lumina, formed by a much-thickened fibrous basement membrane containing 226 fibroblasts and immune cells. Epithelial cells accumulated in multiple layers within the 227 lumina. MAP staining was present but weak, suggesting production of the major milk osmoticon lactose, but relative suppression of milk protein synthesis. Areas of early carcinoma and late carcinoma formed within fields of engorged carcinoma,

230 distinguished by the loss of lumina, poorly defined pseudo-alveoli and milk staining 231 limited to developing necrotic areas. Lung metastases showed a uniform pseudo232 alveolar pattern typical of the early carcinoma stage. These lesions expanded and 233 developed necrotic centres, but the pseudo-alveolar pattern never varied (Fig. 1D). The 
metastasis stained strongly for MAP which accumulated within the pseudo-alveoli and

235 in the interstitial spaces (Fig.1E). Single PyMT positive cells were never seen, the 236 smallest lesions presented as pseudo-alveoli formed from as few as 4 cells, suggesting 237 that metastasis may occur as groups of mammary epithelial cells.

238 Adenoma/MINs and carcinomas were not engorged with milk at day 15 post239 partum or at later times, demonstrating that these features regress dramatically in 240 volume immediately post-partum by reabsorbtion of the engorging-secretions. This is 241 probably responsible for the regressions in tumor volume that we observed by palpation 242 during the post-partum period (SFig1). Tumor regressions and periods of no tumor 243 expansion occurred in $42 \%$ and $42 \%$ of mutant MT mice respectively, compared to $24421 \%$ and $26 \%$ of WT mice respectively. This is consistent with the complete failure of 245 lactation in MT mice ${ }^{15}$ and thus faster loss of these engorged features.

246 We previously reported that the Oas2 mutation caused disruption of Signal 247 Transducer And Activator Of Transcription (Stat) phosphorylation ${ }^{15}$ and we 248 determined if this also occurred when combined with the MMTV-PyMT oncogene in 249 the immediate post-partum period, when OAS2 levels are highest having been induced 250 through pregnancy ${ }^{15}$ (Fig. 2A). Phosphorylated Stat1 (pStat1) was seen as small foci 251 of $\mathrm{DAB}+$ nuclei in all stages of tumor progression and quantification using QuPath ${ }^{25}$ 252 suggested that some MT animals expressed higher pStat1, as reported in non PyMT 253 animals ${ }^{15}$. Phosphorylated Stat3 (pStat3) was expressed at lower frequency in 254 carcinoma epithelial cells compared to cells from the other stages and more frequently 255 in MT glands. Phosphorylated Stat5 (pStat5) was more frequently expressed in 256 hyperplasia and showed a reduction in the frequency of expression as the disease 257 progressed to carcinoma, correlating with milk protein levels. pStat5 was less 258 frequently expressed in MT glands, as previously reported for non PyMT animals ${ }^{15}$. 259 Thus, the effects of MT on Stat activation continue in PyMT animals.

260 We previously reported increased mammary epithelial cell apoptosis in 261 response to MT in non-PyMT mice following parturition ${ }^{15}$. We used staining for 262 cleaved caspase 3 (CC3) to look for this effect in mice also carrying the PyMT oncogene 263 (Fig. 2B). We found no effect when whole glands were analysed without regard to 264 lesion type prompting an analysis within lesion types. The highest rates of apoptosis 265 were seen in engorged MIN compared to the other lesion types. There were no 266 significant differences in apoptosis between MT and WT animals in any of the lesion 
types. This suggests that transformation with PyMT abrogates the apoptotic effects of OAS2 activation.

Effects of MT OAS2 on tumor progression and metastasis.

Cohorts of $20 \mathrm{WT}$ or MT PyMT Oas 2 mice were kept nulliparous or were made pregnant (80 mice total) from 7-9 weeks of age and all pups were removed at birth.

273 Mice were monitored by mammary palpation at twice-weekly intervals. Tumor onset and growth was measured in the major and minor axes using callipers, and mice were euthanized at the estimated ethical endpoint of $10 \%$ tumor burden prior to autopsy. Animal survival to various endpoints was analyzed using Kaplan-Meier survival plots with log-rank $\mathrm{p}$ values and hazard ratios calculated by the Cox proportional hazards model as implemented in GraphPad-Prism (Fig. 3, and SFig. 2 for p values and hazard ratios (HR) of two-way comparisons).

Survival to the age of initial tumor detection (Fig. 3A), showed that tumors in WT parous animals were detected at a younger age than WT nulliparous animals, 66 compared to 78 days $(\mathrm{p}=0.0038)$. MT parous animals also had tumors detected at a younger age than MT nulliparous animals, 65.6 days compared to 77.5 days $(p=0.0019)$. There was no difference in the age of tumor detection between WT and MT animals, either parous or nulliparous. The period from tumor detection to ethical endpoint (Fig. 3B) was not different among WT nulliparous, WT parous or MT parous animals. MT nulliparous animals progressed more quickly than those in the other cohorts, 22.5 days compared to 31 days $(\mathrm{p}=0.002)$ for WT parous, 35 days $(\mathrm{p}<0.0001)$ for MT parous, and 25.5 days $(\mathrm{p}=0.03)$ for WT nulliparous. The age that animals reached their ethical endpoint (Fig. 3C) was not different among WT parous, MT parous and MT nulliparous animals. WT nulliparous reached their ethical endpoint later by 5 days $(p=0.0345), 3$ days $(p=0,034)$ and 4 days $(p=0.18)$ respectively. Overall, parity caused earlier tumor detection but slower tumour progression, opposing effects with the result that parous animals, either MT or WT, reached the ethical endpoint a few days earlier than nulliparous WT animals. The Oas2 mutation had no effect on the age

297 MT nulliparous animals reached the ethical endpoint earlier than nulliparous WT, and 298 at the same age as parous animals. These effects showed HR between 1.8 to 2.9 299 indicating a two- to three-fold increase in risk. 
We examined metastatic burden in two sections of both lungs per mouse from 301 the cohort of mice above, using PyMT IHC to detect metastases and allow measurement 302 of their stained area using QuPath ${ }^{25}$. In the cohorts there was no difference in tumor 303 burden at the ethical endpoint, measured at autopsy by weighing tumors and body 304 weights (BW) from animals euthanized at an estimated 10\% tumor burden by tumor 305 dimensions (Fig. 4A, each symbol is a mouse).

306 Results for the quantification of metastases are plotted on a log scale due to the 307 skewed and thus non-Gaussian distribution of this data, $\mathrm{p}<0.001 \mathrm{~K} 233-70 \mathrm{using}$ the 308 D'Agostino\&Pearson normality test (Fig. 4B). Sections with no lung metastases are 309 indicated as " 0 " at the bottom of the figure as they can't be plotted on a log axis. Error 310 bars show standard error of the mean, but median values (dashed lines) and the Mann311 Whitney nonparametric test of significance are used for comparisons.

312 Pregnancy caused an increase in the proportion of WT mice with metastases, up 313 from 9 of 19 nulliparous WT mice to 15 of 19 parous WT mice ( $\mathrm{p}=0.09$ Fisher's exact 314 test). In contrast, pregnancy made no difference to the number of MT Oas2 mice with 315 a metastasis, 10 of 20 nulliparous MT mice compared to 8 of 18 parous MT mice ( $\mathrm{p}=0.8$ 316 Fisher's exact test). There were half the number of MT mice with metastases than WT 317 mice ( $p=0.04$ Fisher's exact test).

318 The median number of metastases per lung section (Fig. 4B top panel) rose from 3190 in nulliparous WT or MT mice to 6.5 in parous WT mice ( $\mathrm{p}<0.0001$ Mann Whitney), 320 but to just 1 in parous MT mice $(\mathrm{p}=0.0016)$. Parous MT mice had 6.5 fold fewer 321 metastases than WT mice $(\mathrm{p}=0.0124)$. Image analysis was used to quantify the area of 322 lung-metastases as a proportion of lung tissue area (Fig. 4B lower panel). The area of 323 lung alveolar space was excluded from the analysis as individual sections showed 324 variation in the degree of lung inflation at fixation. Parity caused the median area of 325 metastasis in WT lung tissue to increase from 0 to $1.3 \%$, but to just $0.18 \%$ in MT 326 animals, a 7-fold decrease in metastases area $(\mathrm{p}=0.0338)$. We conclude that activation of OAS2 prevented pregnancy from driving metastases to the lung.

Effects of the OAS2 mutation on the immune system.

330 Lung metastasis in the MMTV-PyMT model is highly dependent on innate 331 immune cells ${ }^{18,21-23}$ of monocyte and neutrophil origin which are recruited to tumors 332 where they adopt a pathogenic inflammatory and immunosuppressive state capable of 333 modulating T-cell activity, often called MDSC of granulocyte or polymorphonucleated 
334 neutrophil origin (G- or PMN-MDSC), or monocyte origin (M-MDSC). The 335 development of cell surface markers enabling clear distinction of cells that have 336 assumed the pathogenic state remains the key challenge of this field, and the definition 337 of the pathogenic state is currently limited to functional tests ${ }^{24}$.

338 We undertook a flowcytometric survey of monocytes and granulocytes in 339 tumors (Fig. 5, gating strategy SFig. 4). Monocyte and neutrophil levels showed 340 individual variation, however, we found a rise in the number of monocytes and 341 neutrophils in more than half of the MT parous tumors compared to WT parous tumors 342 and mean levels increased for both cell types ( $\mathrm{p}=0.022$ and $\mathrm{p}=0.0296$ respectively). 343 Non-oncogene carrying mice showed no significant changes in monocyte levels with 344 MT or parity. Neutrophil levels increased significantly in parous animals compared to 345 nulliparous animals ( $\mathrm{p}=0.0571$ and $\mathrm{p}=0.0043$ ) but MT was without effect. The presence 346 of a tumor appeared to reduce the ability of parity to increase neutrophil levels in some 347 mice. As monocyte and neutrophil levels increase in the tumors of parous MT mice, 348 but not in all MT mice, these results suggest that any action of MT on monocytes and 349 neutrophils to reduce metastasis must be to prevent the transition of monocytes and 350 neutrophils to the pathogenic state.

351 To determine if the changes in monocytes and neutrophils altered parameters 352 measured in CD4 and CD8 T cells we surveyed tumors, the draining inguinal lymph 353 node, spleen and thymus. We found great variation among individual mice in most of 354 the measured T-cell parameters, showing that we would require an impractically large 355 cohort size to provide sufficient power to this analysis to detect differences (SFig. 3).

357 Effects of PD-L1 on tumor progression and metastasis.

358 To determine if PD-L1 treatment was more effective in parous mice and 359 whether it interacted with MT, we added PD-L1 treatment to the paradigm used above. 360 Mice received either six IgG or PD-L1 treatments (individual details SFig. 4) when 361 tumors first became palpable and generally coinciding with pregnancy and parity. Mice 362 were monitored with twice weekly measurements of major and minor tumor axis to the 363 ethical end point. Data was analyzed by Kaplan Meier survival analysis with log rank $364 \mathrm{p}$ values and Cox proportional hazards estimation of hazard ratios. All tumor growth 365 profiles are shown in in SFig. 4 and all two-way survival comparisons are shown in 366 SFig. 5. 
PD-L1 or MT had no effect on the age at which tumors were first detected (Fig

368 6A, two-way comparisons and p values SFig. 6). PD-L1 treatment slowed tumor 369 progression in MT mice from detection to endpoint, by 10 days compared to IgG treated 370 mice (Fig. 6B), from a median time of 46 to 56 days $(p=0.0036 \mathrm{HR}=3.8)$. The effect of 371 PD-L1 in MT mice was also apparent at the ethical endpoint (Fig. 6C), where PD-L1 372 treated MT mice had a median age of 62.5 days compared to MT IgG treated of 67 days 373 ( $\mathrm{p}=0.065$ HR 1.9). PD-L1 had no effect in WT mice. Tumors in MT IgG treated mice 374 progressed more quickly to the ethical endpoint than in WT mice, and PD-L1 treatment 375 normalized this so that MT PD-L1 treated mice became indistinguishable from WT 376 mice. Since PD-L1 was ineffective in WT mice on tumor progression, we conclude that 377 MT sensitised the mice to PD-L1 treatment, but by promoting more rapid tumor 378 progression which was then ameliorated by PD-L1.

379 We examined the effect of PD-L1 treatment on metastasis (Fig. 7). Tumor 380 burden was estimated from tumor dimensions and mice were killed at an estimated 10\% 381 BW. Actual tumor burden was measured at autopsy. PD-L1 produced slightly lower 382 burden in both WT $(\mathrm{p}=0.0813)$ and MT mice $(\mathrm{p}=0.0939)$. In WT animals PD-L1 383 treatment did not significantly reduce the number of metastases, but in MT animals a 384 significant 7.4-fold reduction occurred from a median of 29.5 to 4 metastases per 385 section $(\mathrm{p}=0.001)$. The median area of lung-metastases as a proportion of lung tissue 386 area was reduced 9-fold in WT animals from 6.3 to $0.7(\mathrm{p}=0.002)$ and 5-fold in MT 387 animals from 3 to $0.56(\mathrm{p}=0.0002)$. We conclude that MT increased the ability of PD388 L1 treatment to reduce metastases seeding to lung.

389 To determine if PD-L1 was having a greater but transient effect during the 390 treatment period we examined a second cohort of six mice per group immediately after 391 treatment using 2 sections per lung (Fig. 8). Mammary gland weights showed no 392 difference among groups (Fig. 8A). The only group in which any lung sections 393 contained no metastases were MT Oas2 and PD-L1 treated mice, where half the 394 sections were negative ( $\mathrm{p}=0.0373$ Fischer's exact test compared to WT PD-L1 treated). 395 The median number of metastases in WT mice increased 2.8-fold from 16.5 to 45.5, 396 but in MT mice it fell 9.2-fold from 23 to 2.5 (Fig 8B upper panel). There was a large 397 difference in median metastasis number per section between WT (45.5) or MT (2.5) 398 animals treated with PD-L1 ( $\mathrm{p}=0.128)$.

399 Metastases as a percentage of tissue area fell 3.5-fold in WT mice from 3.36\% 400 to $0.95 \%(\mathrm{p}=0.0433)$ and 16 -fold in MT mice from $4 \%$ to $0.25 \%(\mathrm{p}=0.0001)$ (Fig. $8 \mathrm{~B}$ 
401 lower panel). PD-L1 was more effective in MT Oas2 mice. Interestingly the number of 402 metastases seen two weeks after parity were similar to those detected much later at the 403 ethical endpoint, showing that pregnancy and parity increase metastases within an acute 404 period, rather than over the full length of the post-partum period. These data show that 405 PD-L1 treatment caused a reduction of metastases number and area in MT mice.

406 In summary, MT prevented the increase in the number and the tissue area of 407 lung metastases caused by parity and MT enhanced the response to PD-L1 therapy. 408 
The publications on allelic variation in the Oas-RNaseL pathway suggest that

411 inherited alleles that are thought to cause pathway activation produce better control of

412 virally induced tumors, but also of non-viral tumors by providing an enhanced response

413 to de novo dsRNA production from integrated viruses. A separate group of Oas-

414 RNaseL pathway alleles is thought to cause pathway suppression and to be involved in 415 the genesis of prostate cancer. Our results suggest, however, that the same Oas2 alleles 416 may have context dependant effects. In the nulliparous state activation of Oas 2 caused 417 faster primary tumor progression, but in the parous state this effect was lost, and instead 418 suppression of metastases and sensitisation to checkpoint immunotherapy was 419 observed. It is likely that distinct effects of Oas-RNaseL activation within the cells of 420 the epithelium and immune system add complexity to the role of this pathway in cancer. 421 A fully-completed pregnancy remains an independent predictor of breast cancer 422 risk ${ }^{29}$, and pregnancy-associated breast cancer is associated with a $40 \%$ increase in 423 mortality due to increased metastasis ${ }^{29}$, with even higher rates in cases occurring during 424 pregnancy ${ }^{30}$. The period of increased risk caused by pregnancy may last three or more 425 decades for women who have their first child after their mid 30's, but less than a decade 426 for women who have their first child before their early 20's ${ }^{31,32}$. A degree of life-long 427 protection then follows. This age-dependent period of increased risk defines a large 428 proportion of breast cancer cases as associated with pregnancy, however, current 429 clinical practice uses arbitrary post-partum time periods to define pregnancy associated 430 breast cancer, and doesn't distinguish pregnancy-associated breast cancer based on the 431 age-dependent period of increased risk. Regardless, this type of breast cancer has no 432 special therapeutic guidelines.

433 The number of first pregnancies of women over 30 years of age continues to 434 increase especially in developed and developing countries where increasing age at first 435 pregnancy is correlated with increasing female education ${ }^{33,34}$. Breast cancer associated 436 with pregnancy ${ }^{35}$ is one of the main drivers of the increased prevalence of breast cancer $437{ }^{36}$. This effect is compounded by an ongoing decrease in breast feeding, as every 12 438 months decreases breast cancer risk by $4.3 \%$. In developed countries decreases in 439 childbirth and lactation have doubled the cumulative risk of breast cancer, with two 440 thirds of this effect attributable to reduced lactation ${ }^{37}$.

441 The results of this study have direct relevance to the changes in reproduction 442 practices in developed and developing nations. Activation of OAS2 in the MMTV- 
$443 \quad P y M T$ model of breast cancer prevented pregnancy from increasing the number of lung 444 metastases, a finding that establishes the OAS family as therapeutic targets for the 445 development of agents designed to prevent pregnancy from driving breast cancer 446 metastasis. A positive interaction with PD-L1 therapy was also detected, providing 447 impetus for further study to determine if the combination of OAS activation and 448 checkpoint inhibition is of therapeutic relevance for the treatment of breast cancer 449 during pregnancy. A cautionary finding was that in nulliparous mice activation of 450 OAS2 resulted in more rapid primary tumor progression, suggesting that in nulliparous 451 women the use of interferon-inducing agents should be carefully examined, especially 452 for local recurrences. As the mechanisms responsible for the effects of pregnancy and 453 lactation on post-partum breast cancer risk are poorly understood these findings may 454 also have significance for our understanding of pregnancy associated breast cancer. 455 Importantly the MT mice show no pathology other than failed lactation, a rare 456 observation in the interferon-response field which is beset with serious adverse events, 457 suggesting that such a therapy would have a favourable toxicity profile.

458 Our findings may have relevance to breast cancer more generally. We have 459 recently described a pro-metastasis pathology we called involution mimicry ${ }^{38}$ that 460 occurs in response to forced expression of the ETS transcription factor ELF5, the master 461 regulator of lobuloalveolar development during pregnancy, which causes a limited 462 lactation and ongoing involution response in an ELF5 mouse model ${ }^{23}$, but is also seen 463 in breast cancer patients. The ELF5 mouse model shows a similar a engorgement 464 pathology to that we saw following parity in the MT mice and an increase in lung 465 metastasis that is abrogated by neutrophil depletion ${ }^{23}$. We found profound changes in 466 the state of the epithelium, cancer associated fibroblasts (CAFs), endothelial cells and 467 immune cells ${ }^{38}$. Among the CAFs we found populations previously associated with 468 mammary gland involution following lactation, and an analysis of ligand-receptor 469 interactions among these cell types established the existence of a complex regulatory 470 network linking the induction of ELF5 in the epithelium to profound transcriptional 471 changes in the CAFs and endothelial cells, and to the recruitment and M2 polarization 472 of MDSC ${ }^{38}$. Two linked human molecular signatures were discovered in breast cancer 473 patients, a lactation signature and an involution signature. The lactation signature was 474 enriched in the epithelial cell populations and the involution signature was present in 475 both epithelial and stromal populations. The involution signature was prognostic in the 
476 METABRIC cohort ${ }^{38}$. We surmise that elevated ELF5, possibly due to loss of promoter

477 demethylation ${ }^{39}$, drives a limited lactation and involution in these breast cancers.

478

\section{Conclusion}

480

481 Our results raise the possibility that the use of an OAS family activator, or less specific 482 inducers of the interferon response, could reduce the pro-metastases pathology that 483 occurs in a significant number of breast cancers during pregnancy, the immediate post484 partum period and in cases expressing the involution-mimicry phenotype, and that 485 efficacy could be increased by combination with checkpoint immunotherapy. While the 486 magnitude of some of the effects detailed here are modest, that they occur indicates the 487 existence of mechanistic links that may be exploited by new therapeutic strategies. 


\begin{tabular}{|l|l|}
\hline BW & Body weight \\
\hline CAFs & Cancer associated fibroblasts \\
\hline CAR & Carcinoma \\
\hline CC3 & Cleaved Caspase 3 \\
\hline DAB & 3,3'-diaminobenzidine \\
\hline ELF5 & E-74 like factor 5 \\
\hline ENG & Engorged \\
\hline ENU & N-ethyl-N-nitrosourea \\
\hline ETS & E-26 transformation specific \\
\hline FCS & Fetal calf serum \\
\hline FLAD & Failed lobuloalveolar development \\
\hline HR & Hazard ratio \\
\hline IgG & Immuno gamma globulin \\
\hline IHC & immunohistochemistry \\
\hline IP & Intraperitoneal \\
\hline IRF7 & interferon regulatory factor 7 \\
\hline MAP & Milk associated protein \\
\hline MDSC & myeloid derived suppressor cells \\
\hline MIN & Mammary intraepithelial neoplasia \\
\hline MMTV & Mouse mammary tumor virus promoter \\
\hline MT & Mutant \\
\hline Oas2 & oligoadenylate synthetase 2 gene \\
\hline OAS2 & oligoadenylate synthetase 2 protein \\
\hline PBS & Phosphate buffered saline \\
\hline PD-1 & Programmed death receptor 1 \\
\hline PD-L1 & Programmed death-ligand 1 \\
\hline PI3K & Phosphoinositide 3-kinase \\
\hline PLC-gamma & Phospho lipase C \\
\hline polyIC & polyinosinic-polycytidylic acid \\
\hline PyMT & polyoma middle T protein \\
\hline
\end{tabular}




\begin{tabular}{|l|l|}
\hline PyMT & polyoma middle T oncogene \\
\hline RBC & Red blood cells \\
\hline RIG1 & retinoic acid induced gene 1 \\
\hline RNase-L & latent ribonuclease \\
\hline RPMI & Roswell Park Medical Institute \\
\hline SHC & Src homology 2 domain-containing \\
\hline SRC & Rous sarcoma virus family kinases \\
\hline TAZ & Tafazzin \\
\hline WT & Wild type \\
\hline
\end{tabular}

491

492

493 


\section{Declarations}

495 Ethics approval and consent to participate.

496 All mice were housed in specific pathogen-free conditions at the Australian

497 BioResources and the Biological testing Facility of the Garvan Institute, with all animal

498 experiments carried out according to guidelines contained within the NSW (Australia)

499 Animal Research Act 1985, the NSW (Australia) Animal Research Regulation 2010

500 and the Australian code of practice for the care and use of animals for scientific

501 purposes, (8th Edition 2013, National Health and Medical Research Council

502 (Australia)) and approved by the Garvan/St Vincent's Animal Ethics and

503 Experimentation Committees (approvals 14/27,16/26, 17/23, 18/36).

504 Consent for publication.

505 Not applicable.

506 Availability of data and materials.

507 The datasets used and/or analysed during the current study are available from the

508 corresponding author on reasonable request.

509 Competing interests.

510 The authors declare that they have no competing interests.

511 Funding.

512 This work was supported by grants from the Congress Directed Medical Research

513 Program (BC995364 and DAMD17-01-1-0241), Cure Cancer Australia Foundation,

514 NHMRC Australia (projects 1047149, Fellowships 545805, 481310, 1043400), the

515 Australian Research Council Discovery Project (DP110102288), Fellowships (ECF-

516 13-08 and ECF-16-022) from the National Breast Cancer Foundation, Banque

517 Nationale de Paris-Paribas Australia and New Zealand, Mostyn Family Foundation,

518 Cue Clothing Co., Estee Lauder Australia, Sutton's Motors Sydney and the RT Hall

519 Trust.

520 Authors' contributions.

521 SRO and CJO are joint senior authors. All authors contributed to the experimentation

522 and writing of the manuscript. All authors reviewed drafts of the manuscript and

523 approved the final version.

524 Acknowledgements.

525 The authors acknowledge the excellent work of the staff of Australian BioResources

526 and the Biological Testing Facility of the Garvan Institute. 
530 Figure 1. Effects of pregnancy on lesion histopathology.

531 Panel A, Milk associated protein (MAP) IHC staining of a number 4 mammary gland 532 at day 3 post-partum from a 9-week-old dam. Inguinal region on the right-hand side, 533 dorsal region on the left-hand side. Lesions identified and named by Lin et al. ${ }^{18}$ to be

534 characteristic of disease progression are circled in yellow and are shown at higher 535 magnification below. Failed lobuloalveolar development (FLAD) is indistinguishable 536 from hyperplasia. Panel B, Corresponding lesion IHC staining for PyMT protein. Panel 537 C, Novel histopathological features seen in the immediate post-partum period, MAP 538 IHC of a whole $2^{\text {nd }}$ and $3^{\text {rd }}$ mammary glands shown in the centre panel and H\&E at 539 higher magnification of the circled features shown either side. Panel D. PyMT staining 540 of metastases, Panel E, MAP staining of metastases.

Figure 2. Stat activation and apoptosis during tumor progression in parous mice and the effect of MT Oas2.

544 Panel A. The phosphorylation of the indicated Stat proteins is shown by specific 545 phospho-Stat IHC and DAB staining, within the lesions defined in Fig. 1. QuPath was 546 used to quantify overall mammary gland pStat nuclear positivity in MT and WT glands. 547 Error bars are standard error of the mean, MT Stat1 data is not Gaussian (KS p=0.03) 548 and so the Mann-Whitney $U$ test is used to calculate the $\mathrm{p}$ value. Stat3 and Stat5 $\mathrm{p}$ 549 values were calculated using Student's t-test. Panel B. Cleaved caspase 3 (CC3) IHC 550 was used to quantify the proportion of apoptotic cells (CC3\% + cells, left hand panel), 551 and the proportion of pixels positive for CC3 staining (CC3\%+ pixels, right hand 552 panel), in the indicated lesion subtypes abbreviated as HYP.; hyperplasia, MIN; 553 mammary intraepithelial neoplasia, ENG.; Engorged, CAR.; carcinoma. All 554 comparisons within lesion subtypes for CC3 between MT and WT are nonsignificant 555 using Student's t-test. Figure 3. Effect of MT Oas 2 and parity on primary tumor initiation and expansion.

558 Kaplan-Meier survival analysis for the indicated periods and endpoints, and for the 559 indicated genotypes (MT, mutant Oas2; WT wild type Oas2), and parity status of 560 mouse cohorts (20 per group). Mammary glands were palpated twice weekly and tumor 561 growth was measured, as detailed in Supplementary Figure 1. Two-way Kaplan Meier 
curve comparisons and $\mathrm{p}$ values shown in Supplementary Figure 2, n=19 MT parous, 21 WT parous, 20 MT nulliparous and 19 WT nulliparous.

\section{Figure 4. Effect of MT Oas2 and parity on lung metastases.}

Panel A, actual tumor burden of the cohorts. All tumors were excised and weighed at autopsy, which was initiated when estimates of tumor volume calculated from calliper measurements reached $10 \%$ of body weight $(\mathrm{BW})$. Abbreviations are MT, mutant Oas2; WT wild type Oas2; np, nulliparous; p, parous. Error bars are standard error of the mean and $p$ values for the two-way comparisons indicated by the extremities of the lines were calculated using Student's t-test. Each symbol is the total tumor burden for a mouse. Panel B, top panel, the number of lung metastases per section counted manually using two sections per lung, $100 \mu \mathrm{m}$ apart, and bottom panel, the area of DAB + cells stained by IHC for PyMT and quantified by QuPath, for the indicated genotypes and parity status of the mouse cohorts (20 per group). Error bars are standard error of the mean, median value is indicated by the broken bar and $\mathrm{p}$ values were calculated using Mann-Whitney U test. Sections without metastases (which can't be plotted on a log axis) are shown at the bottom of the figure marked "0". Each symbol is a section.

\section{Figure 5. Effects of MT Oas2 on T cells, neutrophils and granulocytes.}

A screening of monocytes and neutrophils also known as myeloid derived suppressor cells (MDSC) was undertaken in mammary tumors. Granulocytes and neutrophils levels were quantified in the third (3MG) or fourth (4MG) and results are combined for statistical analysis. Axes show percentage of cells within the previous gate and gating strategy is shown in SFig. 4. Error bars are standard error of the mean and $p$ values calculated by Student's t-test for the two-way comparisons indicated by the extremities of the lines. Abbreviations are MT, mutant Oas2; WT wild type Oas2; np, nulliparous; p, parous.

Figure 6. Effect of PD-L1 and MT Oas2 on primary tumor initiation and expansion in parous mice.

Kaplan-Meier survival analysis for the indicated periods and endpoints, and for the indicated genotypes, MT, mutant Oas2; WT wild type Oas2 and treatments (PD-L1 or 
IgG IP twice weekly), of mouse cohorts (20 per group). All mammary glands were palpated twice weekly and tumor growth was measured by callipers. Individual tumor growth profiles are shown in as shown in Supplementary Figure 5. Two-way KaplanMeier comparisons and $\mathrm{p}$ values are shown in Supplementary Figure 6, n=8 WT PDL1, 8 WT IgG, 14 MT PD-L1, 15 MT IgG.

600

601 Figure 7. Effect of PD-L1 and MT Oas2 on lung metastases in parous mice at the 602 ethical endpoint.

603 Panel A, actual tumor burden of the cohorts as a \% of body weight (BW). All tumors 604 were excised and weighed at autopsy, which was initiated when estimates of tumor 605 volume calculated from calliper measurements reached $10 \%$ of body weight. Error bars 606 are standard error of the mean and $p$ values were calculated using Student's t-test. Panel 607 B, the number of lung metastases per section, counted manually using two sections per 608 lung $100 \mu \mathrm{m}$ apart, and the area of DAB + cells stained by IHC for PyMT and quantified 609 by QuPath, for the indicated genotypes and treatments (PD-L1 or IgG IP twice weekly).

610 Mice without metastases (which can't be plotted on a log axis) are shown at the bottom 611 of the figure marked "0". Error bars are standard error of the mean, median value is 612 indicated by the broken bar and $\mathrm{p}$ values were calculated using Mann-Whitney U test 613 for the two-way comparisons indicated by the extremities of the line. Abbreviations are 614 MT, mutant Oas2; WT wild type Oas2

Figure 8. Effect of PD-L1 and MT Oas2 on lung metastases in parous mice immediately following PD-L1 treatment.

618 Panel A, Mammary gland (MG) weight as a percentage of body weight (BW). All 619 tumors were excised and weighed at autopsy at the completion of PD-L1 treatment, 620 usually 2 weeks post-partum. Error bars are standard error of the mean and p values 621 were calculated using Student's t-test. Panel B, the number of lung metastases per section (two sections per lung) counted manually, and the area of $\mathrm{DAB}+$ cells stained

623 by IHC for PyMT and quantified by QuPath, for the indicated genotypes and treatments 624 (PD-L1 or IgG IP twice weekly), of mouse cohorts. Mice without metastases (which 625 can't be plotted on a log axis) are shown at the bottom of the figure marked " 0 ". Error 626 bars are standard error of the mean, median value is indicated by the broken bar and $\mathrm{p}$ 
values were calculated using Mann-Whitney U test. Abbreviations are MT, mutant Oas2; WT wild type Oas2 parous mice.

632 Examples of tumor growth curves of individual mice. The left and right hand side $2^{\text {nd }} / 3^{\text {rd }}$ 633 and $4^{\text {th }}$ mammary glands were palpated twice weekly and tumor growth was estimated 634 by measurement of the major and minor axis of each gland using callipers. Y axis is 635 placed at parity indicated on the $\mathrm{x}$ axis as day 0 . Numbers show the total number of 636 glands with tumors detected, the number that showed a period of no growth, and the 637 number that showed regression at or following parity. W, wild type; $M, M T ; W / W$, 638 homozygous wild type; M/M, homozygous MT.

Supplementary Figure 2. Effect of MT Oas2 on primary tumor initiation and expansion in nulliparous and parous mice.

642 Two-way Kaplan-Meier survival analysis for the indicated periods and endpoints, and 643 for the indicated genotypes, WT wildtype Oas2, MT mutant Oas2, and parity status of 644 mouse cohorts (20 per group). P values and hazard ratios (HR) calculated by the Log645 Rank test using GraphPad Prism. n=19 MT parous, 21 WT parous, 20 MT nulliparous 646 and 19 WT nulliparous.

\section{Supplementary Figure 3. Effects of MT Oas2 on T cells in parous mice.}

A screening of various T-cell parameters was undertaken in mammary tumors, lymph nodes, spleen and thymus. Error bars are standard error of the mean and $p$ values calculated by Student's t-test (all non significant). Axes represent \% of total cells passing the previous gate. Genotypes, WT/WT homozygous wildtype Oas2, MT/MT homozygous mutant Oas2.

Supplementary Figure 4. Flowcytometry gating strategy for monocytes and neutrophils known as myeloid derived suppressor cells.

657 Series of gates used to quantify monocytes and neutrophils using flow cytometry.

659 Supplementary Figure 5. Effect of PD-L1 and MT Oas2 on primary tumor 660 initiation and expansion in parous mice. 
661 Examples of tumor growth curves of individual mice. The $2^{\text {nd }} / 3^{\text {rd }}$ and $4^{\text {th }}$ mammary 662 glands were palpated twice weekly and tumor growth was estimated by measurement 663 of the major and minor axis of individual tumors using callipers. $Y$ axis is placed at the 664 day of tumor detection on the $\mathrm{x}$ axis as day 0. Black diamonds show a treatment with 665 IP IgG or PD-L1 antibodies and red diamonds indicate parity. WT=wild type, MT=MT 666 Oas2 MT/MT = homozygous MT Oas2.

668 Supplementary Figure 6. Effect of PD-L1 and MT Oas2 on primary tumor 669 initiation and expansion in parous mice.

670 Two-way Kaplan-Meier survival analysis for the indicated periods and endpoints, and

671 for the indicated genotypes and treatments (PD-L1 or IgG IP), of mouse cohorts. P

672 values and hazard ratios (HR) calculated by the Log-Rank test using GraphPad Prism.

$673 \mathrm{n}=8$ WT PD-L1, 8 WT IgG, 14 MT PD-L1, 15 MT IgG.

675 Supplementary Table 1. Antibodies, concentration and antigen retrieval 676 conditions for immunohistochemistry.

677 All reagents were from Leica BOND or DAKO for automated or manual IHC (as 678 specified). Visualization of antigen: antibody complexes was performed using the $679 \mathrm{DAB}+$ liquid Substrate chromogen system (K3467).

680

\begin{tabular}{|c|c|c|c|c|c|}
\hline Antigen & $\begin{array}{l}\text { Primary } \\
\text { Antibody } \\
\text { Supplier, Cat \# }\end{array}$ & $\begin{array}{l}\text { Primary Ab } \\
\text { Concentration } \\
\text { \& Incubation }\end{array}$ & $\begin{array}{l}\text { Detection } \\
\text { System }\end{array}$ & $\begin{array}{l}\text { Antigen } \\
\text { Retrieval }\end{array}$ & $\begin{array}{l}\text { Secondary } \mathrm{Ab} \\
(\mathrm{cat} \#)\end{array}$ \\
\hline $\begin{array}{l}\text { Polyoma } \\
\text { Virus, } \\
\text { Middle } \mathrm{T} \\
\text { Antigen }\end{array}$ & $\begin{array}{l}\text { Novus } \\
\text { Biologicals, } \\
\text { NB100-2749 }\end{array}$ & $1: 300,60 \mathrm{~min}$ & $\begin{array}{l}\text { BOND } \\
\text { Polymer } \\
\text { Refine } \\
\text { (DS9800) }\end{array}$ & $\begin{array}{l}\text { HIER } 30 \mathrm{~min} \text {, } \\
\text { ER2 (EDTA } \\
\text { pH9) } 100^{\circ} \mathrm{C}\end{array}$ & $\begin{array}{l}\text { Vector Labs } \\
\text { Rabbit anti-Rat } \\
(\text { BA-4001-.5) } \\
1: 200\end{array}$ \\
\hline $\begin{array}{l}\text { Phospho- } \\
\text { Stat1 } \\
\text { (Y701) }\end{array}$ & $\begin{array}{l}\text { Cell } \\
\text { Signalling, } \\
9167\end{array}$ & $1: 400,60 \mathrm{~min}$ & $\begin{array}{l}\text { BOND } \\
\text { Polymer } \\
\text { Refine } \\
\text { (DS9800) }\end{array}$ & $\begin{array}{l}\text { HIER } 30 \mathrm{~min} \text {, } \\
\text { ER2 (EDTA } \\
\text { pH9) } 100^{\circ} \mathrm{C}\end{array}$ & $\begin{array}{l}\text { BOND Rab } \\
\text { Polymer only }\end{array}$ \\
\hline
\end{tabular}




\begin{tabular}{|c|c|c|c|c|c|}
\hline $\begin{array}{l}\text { Phospho- } \\
\text { Stat3 } \\
\text { (Y705) }\end{array}$ & $\begin{array}{l}\text { Cell } \\
\text { Signalling, } \\
9145\end{array}$ & $1: 400,60 \mathrm{~min}$ & $\begin{array}{l}\text { BOND } \\
\text { Polymer } \\
\text { Refine } \\
\text { (DS9800) }\end{array}$ & $\begin{array}{l}\text { HIER } 30 \mathrm{~min} \text {, } \\
\text { ER2 } \quad \text { (EDTA } \\
\text { pH9) } 100^{\circ} \mathrm{C}\end{array}$ & $\begin{array}{l}\text { BOND Rab } \\
\text { Polymer only }\end{array}$ \\
\hline $\begin{array}{l}\text { Phospho- } \\
\text { Stat5 } \\
\text { (Y964) }\end{array}$ & $\begin{array}{l}\text { Cell } \\
\text { Signalling, } \\
9351\end{array}$ & $1: 400,60 \mathrm{~min}$ & $\begin{array}{l}\text { BOND } \\
\text { Polymer } \\
\text { Refine } \\
\text { (DS9800) }\end{array}$ & $\begin{array}{l}\text { HIER } 30 \mathrm{~min} \text {, } \\
\text { ER2 } \\
\text { pH9) } 100^{\circ} \mathrm{C}\end{array}$ & $\begin{array}{l}\text { BOND Rab } \\
\text { Polymer only }\end{array}$ \\
\hline $\begin{array}{l}\text { Cleaved } \\
\text { Caspase } 3\end{array}$ & $\begin{array}{l}\text { Cell } \\
\text { Signalling, } \\
9664\end{array}$ & $1: 800,60 \mathrm{~min}$ & $\begin{array}{l}\text { BOND } \\
\text { Polymer } \\
\text { Refine } \\
\text { (DS9800) }\end{array}$ & $\begin{array}{l}\text { HIER } 20 \mathrm{~min} \text {, } \\
\text { ER2 } \\
\text { pH9) } 100^{\circ} \mathrm{C}\end{array}$ & $\begin{array}{l}\text { BOND Rab } \\
\text { Polymer only }\end{array}$ \\
\hline $\operatorname{CD} 8 \alpha$ & $\begin{array}{l}\text { Cell } \\
\text { Signalling, } \\
98941\end{array}$ & $1: 200,30 \mathrm{~min}$ & $\begin{array}{l}\text { BOND } \\
\text { Polymer } \\
\text { Refine } \\
\text { (DS9800) }\end{array}$ & $\begin{array}{l}\text { HIER 20min, } \\
\text { ER2 (EDTA } \\
\text { pH9) } 100^{\circ} \mathrm{C}\end{array}$ & $\begin{array}{l}\text { BOND Rab } \\
\text { Polymer only }\end{array}$ \\
\hline $\begin{array}{l}\text { Milk } \\
\text { Associated } \\
\text { Protein }\end{array}$ & $\begin{array}{l}\text { Accurate } \\
\text { Chemical \& } \\
\text { Scientific Co., } \\
\text { YNRMTM }\end{array}$ & $\begin{array}{l}1: 12,000, \\
60 \mathrm{~min}\end{array}$ & $\begin{array}{l}\text { DAKO } \\
\text { manual } \\
\text { IHC }\end{array}$ & $\begin{array}{l}\text { DAKO } \\
\text { S1699, } 100^{\circ} \mathrm{C} \\
\text { water bath, } \\
20 \mathrm{~min}\end{array}$ & $\begin{array}{ll}\text { Envision } & \text { Rab } \\
(\mathrm{K} 4009) & \end{array}$ \\
\hline CD45 & $\begin{array}{l}\text { BD } \\
\text { Pharmigen, } \\
\text { BD553077 }\end{array}$ & $1: 200,60 \mathrm{~min}$ & $\begin{array}{l}\text { DAKO \& } \\
\text { Vector } \\
\text { Labs } \\
\text { manual } \\
\text { IHC }\end{array}$ & $\begin{array}{l}\text { DAKO } \\
\text { S1699, } \\
100^{\circ} \mathrm{C} \\
\text { water } \\
20 \mathrm{~min}\end{array}$ & \begin{tabular}{l}
\multicolumn{2}{l}{ VECTASTAIN } \\
Elite \\
HRP \\
$6100)$
\end{tabular} \\
\hline
\end{tabular}

\section{Supplementary Table 2. Antibodies used for flow cytometry.}

Panel name, antibody name by antigen recognised and conjugated fluorochrome, the antibody supplier and catalogue number and final diluted concentration for each is shown.

\begin{tabular}{|l|l|l|l|}
\hline Antibody Panel & Antigen \& Fluorochrome & Supplier, Cat \# & $\begin{array}{l}\text { Antibody } \\
\text { Concentration }\end{array}$ \\
\hline B \& T Cell Panel & & $\begin{array}{l}\text { BD Biosciences, } \\
561859\end{array}$ & $1 / 300$ \\
\hline & CD44 FITC & $\begin{array}{l}\text { BioLegend, } \\
119704\end{array}$ & $1 / 200$ \\
\hline & CD366 (Tim-3) PE & \multicolumn{2}{|l}{} \\
\hline
\end{tabular}




\begin{tabular}{|c|c|c|c|}
\hline & CD3 PerCP-Cy5.5 & $\begin{array}{l}\text { BioLegend, } \\
100217\end{array}$ & $1 / 200$ \\
\hline & CD279 (PD-1) PE-Cy7 & $\begin{array}{l}\text { eBioscience, 25- } \\
\text { 9985-82 }\end{array}$ & $1 / 400$ \\
\hline & CD25 APC & $\begin{array}{l}\text { BD Biosciences, } \\
557192\end{array}$ & $1 / 100$ \\
\hline & TCR $\beta$ chain APC -Cy7 & $\begin{array}{l}\text { BioLegend, } \\
109220\end{array}$ & $1 / 400$ \\
\hline & CD44 Pacific blue & $\begin{array}{l}\text { BioLegend, } \\
103020\end{array}$ & $1 / 300$ \\
\hline & $\begin{array}{l}\text { Zombie Aqua }{ }^{\mathrm{TM}} \text { Fixable Viability } \\
\text { Kit }\end{array}$ & $\begin{array}{l}\text { BioLegend, } \\
423101\end{array}$ & $1 / 500$ \\
\hline & CD62L BV605 & $\begin{array}{l}\text { BioLegend, } \\
104438\end{array}$ & $1 / 800$ \\
\hline & CD45R (B220) BV786 & $\begin{array}{l}\text { BD Biosciences, } \\
563894\end{array}$ & $1 / 300$ \\
\hline & CD8a BUV395 & $\begin{array}{l}\text { BD Biosciences, } \\
563786\end{array}$ & $1 / 300$ \\
\hline & CD4 BUV737 & $\begin{array}{l}\text { BD Biosciences, } \\
564306\end{array}$ & $1 / 300$ \\
\hline \multirow[t]{12}{*}{ T Cell Panel } & CD28 FITC & $\begin{array}{l}\text { BioLegend, } \\
122007\end{array}$ & $1 / 200$ \\
\hline & CD25 PE & $\begin{array}{l}\text { eBioscience, } 12- \\
0251-83\end{array}$ & $1 / 200$ \\
\hline & CD62L PerCP-Cy5.5 & $\begin{array}{l}\text { BD Biosciences, } \\
560513\end{array}$ & $1 / 200$ \\
\hline & CD279 (PD-1) PE-Cy7 & $\begin{array}{l}\text { eBioscience, 25- } \\
\text { 9985-82 }\end{array}$ & $1 / 400$ \\
\hline & CD152 (CTLA4) APC & $\begin{array}{l}\text { eBioscience, 17- } \\
1522-82\end{array}$ & $1 / 100$ \\
\hline & CD278 ICOS APC-Cy7 (e780) & $\begin{array}{l}\text { Australian } \\
\text { Bioresearch, } \\
313529 \\
\end{array}$ & $1 / 400$ \\
\hline & Foxp3 eFLour450 & $\begin{array}{l}\text { eBioscience, } 48- \\
5773-80\end{array}$ & $1 / 100$ \\
\hline & $\begin{array}{l}\text { Zombie Aqua }{ }^{\mathrm{TM}} \text { Fixable Viability } \\
\text { Kit }\end{array}$ & $\begin{array}{l}\text { BioLegend, } \\
423101\end{array}$ & $1 / 500$ \\
\hline & CD44 BV605 & $\begin{array}{l}\text { BD Biosciences, } \\
563058\end{array}$ & $1 / 200$ \\
\hline & TCRb Biotin \& BV786 Strepavidin & $\begin{array}{l}\text { BD Biosciences, } \\
553169 \& \\
563858\end{array}$ & $\begin{array}{l}1 / 300 \\
\text { (Primary } \mathrm{Ab})\end{array}$ \\
\hline & CD8a BUV395 & $\begin{array}{l}\text { BD Biosciences, } \\
563786\end{array}$ & $1 / 300$ \\
\hline & CD4 BUV737 & $\begin{array}{l}\text { BD Biosciences, } \\
564306\end{array}$ & $1 / 300$ \\
\hline Myeloid Panel & Gr1 PE & $\begin{array}{l}\text { BioLegend, } \\
108408\end{array}$ & $1 / 200$ \\
\hline
\end{tabular}




\begin{tabular}{|l|l|l|l|}
\hline & & $\begin{array}{l}\text { BioLegend, } \\
128011\end{array}$ & $1 / 200$ \\
\hline & Ly6C PerCP-Cy5.5 & $\begin{array}{l}\text { BioLegend, } \\
103114\end{array}$ & $1 / 200$ \\
\hline & CD45 PE-Cy7 & $\begin{array}{l}\text { BioLegend, } \\
123116\end{array}$ & $1 / 200$ \\
\hline & F4/80 APC & $\begin{array}{l}\text { eBioscience, } 47- \\
0122-82\end{array}$ & $1 / 200$ \\
\hline & CD11b APC e780 & BioLegend, & \\
& Zombie Aqua ${ }^{\text {TM }}$ Fixable Viability & 423101 & $1 / 500$ \\
\hline & Kit & $\begin{array}{l}\text { BD Biosciences, } \\
563979\end{array}$ & $1 / 200$ \\
\hline & Ly6G BV711 & & \\
\hline
\end{tabular}




\section{References.}

1. Parker, B.S., Rautela, J. \& Hertzog, P.J. Antitumour actions of interferons: implications for cancer therapy. Nat Rev Cancer 16, 131-144 (2016).

2. Benci, J.L. et al. Opposing Functions of Interferon Coordinate Adaptive and Innate Immune Responses to Cancer Immune Checkpoint Blockade. Cell 178, 933-948 e914 (2019).

3. Borden, E.C. Interferons alpha and beta in cancer: therapeutic

opportunities from new insights. Nat Rev Drug Discov 18, 219-234 (2019).

4. Kyi, C. et al. Therapeutic Immune Modulation against Solid Cancers with Intratumoral Poly-ICLC: A Pilot Trial. Clinical cancer research : an official journal of the American Association for Cancer Research 24, 4937-4948 (2018).

5. Nagato, T., Lee, Y.R., Harabuchi, Y. \& Celis, E. Combinatorial immunotherapy of polyinosinic-polycytidylic acid and blockade of programmed death-ligand 1 induce effective CD8 T-cell responses against established tumors. Clinical cancer research : an official journal of the American Association for Cancer Research 20, 1223-1234 (2014).

6. Silverman, R.H. Viral encounters with 2 ',5'-oligoadenylate synthetase and RNase L during the interferon antiviral response. Journal of virology $\mathbf{8 1}$, 12720-12729 (2007).

7. Donovan, J., Dufner, M. \& Korennykh, A. Structural basis for cytosolic double-stranded RNA surveillance by human oligoadenylate synthetase 1 . Proceedings of the National Academy of Sciences of the United States of America 110, 1652-1657 (2013).

8. Chakrabarti, A., Jha, B.K. \& Silverman, R.H. New insights into the role of RNase L in innate immunity. Journal of interferon \& cytokine research : the official journal of the International Society for Interferon and Cytokine Research 31, 49-57 (2011).

9. Madsen, B.E. et al. Germline mutation in RNASEL predicts increased risk of head and neck, uterine cervix and breast cancer. PloS one 3, e2492 (2008).

10. Banerjee, S. et al. OAS-RNase L innate immune pathway mediates the cytotoxicity of a DNA-demethylating drug. Proceedings of the National Academy of Sciences of the United States of America 116, 5071-5076 (2019).

11. Fesinmeyer, M.D., Kwon, E.M., Fu, R., Ostrander, E.A. \& Stanford, J.L. Genetic variation in RNASEL and risk for prostate cancer in a populationbased case-control study. Prostate 71, 1538-1547 (2011).

12. Meyer, M.S. et al. Genetic variation in RNASEL associated with prostate cancer risk and progression. Carcinogenesis 31, 1597-1603 (2010).

13. Nguyen-Dumont, T. et al. Is RNASEL:p.Glu265* a modifier of early-onset breast cancer risk for carriers of high-risk mutations? BMC cancer 18, 165 (2018).

14. Yin, H., Jiang, Z., Wang, S. \& Zhang, P. IFN-gamma restores the impaired function of RNase L and induces mitochondria-mediated apoptosis in lung cancer. Cell Death Dis 10, 642 (2019). 
15. Oakes, S.R. et al. A mutation in the viral sensor 2'-5'-oligoadenylate synthetase 2 causes failure of lactation. PLoS genetics 13, e1007072 (2017).

16. Guy, C.T., Cardiff, R.D. \& Muller, W.J. Induction of mammary tumors by expression of polyomavirus middle $\mathrm{T}$ oncogene: a transgenic mouse model for metastatic disease. Mol Cell Biol 12, 954-961 (1992).

17. Fluck, M.M. \& Schaffhausen, B.S. Lessons in signaling and tumorigenesis from polyomavirus middle T antigen. Microbiol Mol Biol Rev 73, 542-563, Table of Contents (2009).

18. Lin, E.Y. et al. Progression to malignancy in the polyoma middle T oncoprotein mouse breast cancer model provides a reliable model for human diseases. The American journal of pathology 163, 2113-2126 (2003).

19. Allen, E. et al. Combined antiangiogenic and anti-PD-L1 therapy stimulates tumor immunity through HEV formation. Sci Transl Med 9 (2017).

20. Messenheimer, D.J. et al. Timing of PD-1 Blockade Is Critical to Effective Combination Immunotherapy with Anti-OX40. Clinical cancer research : an official journal of the American Association for Cancer Research 23, 6165-6177 (2017).

21. Lin, E.Y. et al. Vascular endothelial growth factor restores delayed tumor progression in tumors depleted of macrophages. Mol Oncol 1, 288-302 (2007).

22. Lin, E.Y., Nguyen, A.V., Russell, R.G. \& Pollard, J.W. Colony-stimulating factor 1 promotes progression of mammary tumors to malignancy. J Exp Med 193, 727-740 (2001).

23. Gallego-Ortega, D. et al. ELF5 drives lung metastasis in luminal breast cancer through recruitment of Gr1+ CD11b+ myeloid-derived suppressor cells. PLoS biology 13, e1002330 (2015).

24. Veglia, F., Sanseviero, E. \& Gabrilovich, D.I. Myeloid-derived suppressor cells in the era of increasing myeloid cell diversity. Nature reviews. Immunology (2021).

25. Bankhead, P. et al. QuPath: Open source software for digital pathology image analysis. Sci Rep 7, 16878 (2017).

26. Bradley, L.M., Atkins, G.G. \& Swain, S.L. Long-term CD4+ memory T cells from the spleen lack MEL-14, the lymph node homing receptor. Journal of immunology 148, 324-331 (1992).

27. MacDonald, H.R., Budd, R.C. \& Cerottini, J.C. Pgp-1 (Ly 24) as a marker of murine memory T lymphocytes. Curr Top Microbiol Immunol 159, 97-109 (1990).

28. Rose, S., Misharin, A. \& Perlman, H. A novel Ly6C/Ly6G-based strategy to analyze the mouse splenic myeloid compartment. Cytometry A 81, 343350 (2012).

29. Daling, J.R., Malone, K.E., Doody, D.R., Anderson, B.O. \& Porter, P.L. The relation of reproductive factors to mortality from breast cancer. Cancer Epidemiol Biomarkers Prev 11, 235-241 (2002).

30. Whiteman, M.K. et al. Reproductive history and mortality after breast cancer diagnosis. Obstet Gynecol 104, 146-154 (2004). 
31. Albrektsen, G., Heuch, I., Hansen, S. \& Kvale, G. Breast cancer risk by age at birth, time since birth and time intervals between births: exploring interaction effects. Br J Cancer 92, 167-175 (2005).

32. Colditz, G.A. \& Rosner, B. Cumulative risk of breast cancer to age 70 years according to risk factor status: data from the Nurses' Health Study. American journal of epidemiology 152, 950-964 (2000).

33. Mathews, T. \& Hamilton, B. Mean age of mothers is on the rise: United States, 2000-2014. NCHS Data Brief No 232 (2016).

34. Studies, A.I.o.F. Births in Australia-Age of new mothers. (2018).

35. Lee, G.E., Mayer, E.L. \& Partridge, A. Prognosis of pregnancy-associated breast cancer. Breast cancer research and treatment 163, 417-421 (2017).

36. DeSantis, C.E. et al. International Variation in Female Breast Cancer Incidence and Mortality Rates. Cancer Epidemiol Biomarkers Prev 24, 1495-1506 (2015).

37. Collaborative Group on Hormonal Factors in Breast, C. Breast cancer and breastfeeding: collaborative reanalysis of individual data from 47 epidemiological studies in 30 countries, including 50302 women with breast cancer and 96973 women without the disease. Lancet 360, 187195 (2002).

38. Valdes-Mora, F. et al. Single-cell RNAseq uncovers involution mimicry as an aberrant development pathway during breast cancer metastasis. Cell Reports 35, 108945 (2021).

39. Lee, H.J. et al. Lineage specific methylation of the Elf5 promoter in mammary epithelial cells. Stem Cells 29, 1611-1619 (2011). 
A. Tumor progression and milk protein synthesis.

MAP IHC

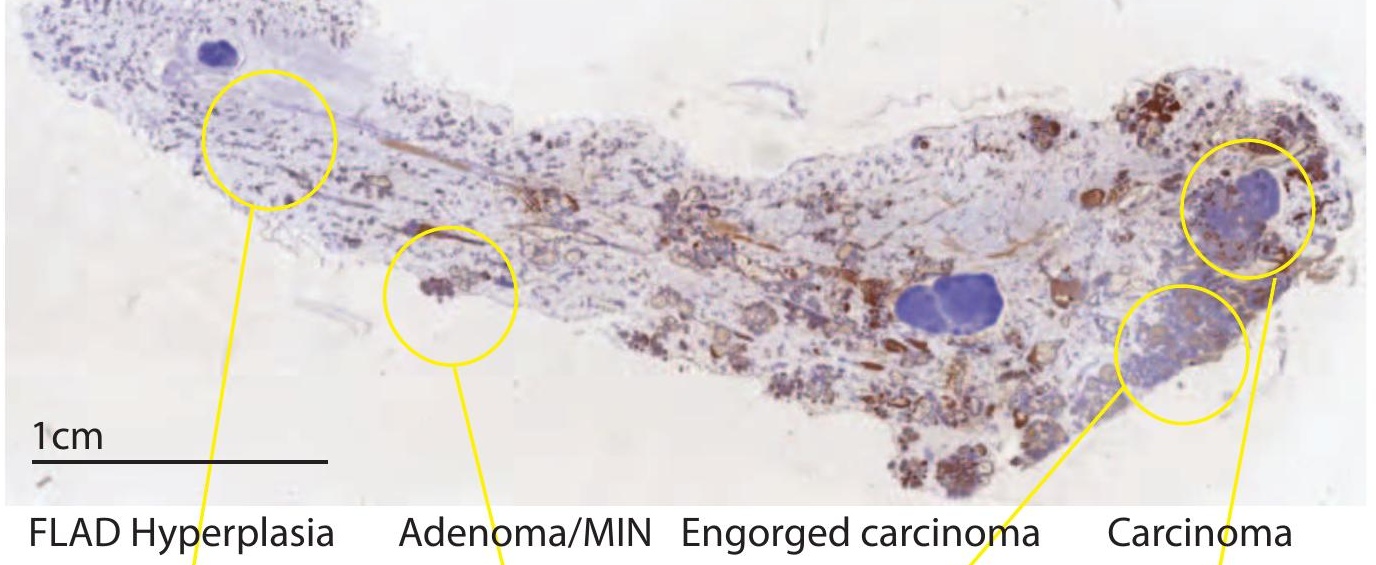

B. PyMT IHC

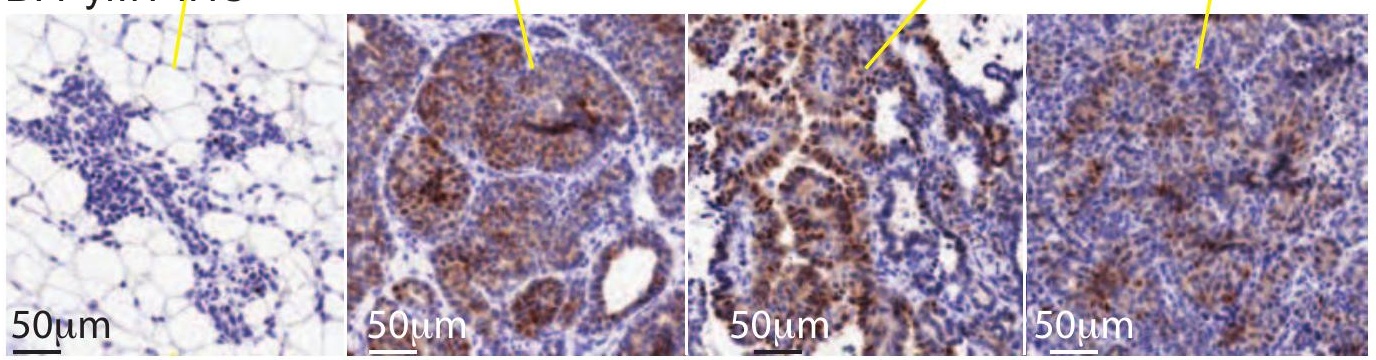

C. Novel parous features
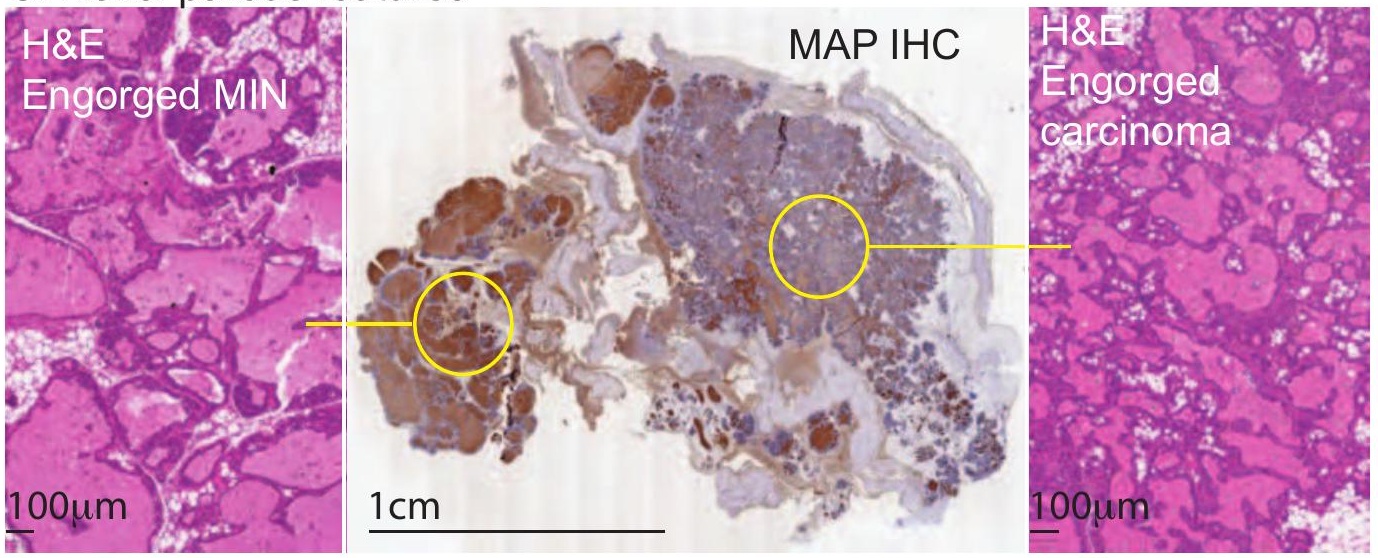

D. Lung Metastasis PyMT IHC

E. Lung Metastasis MAP IHC

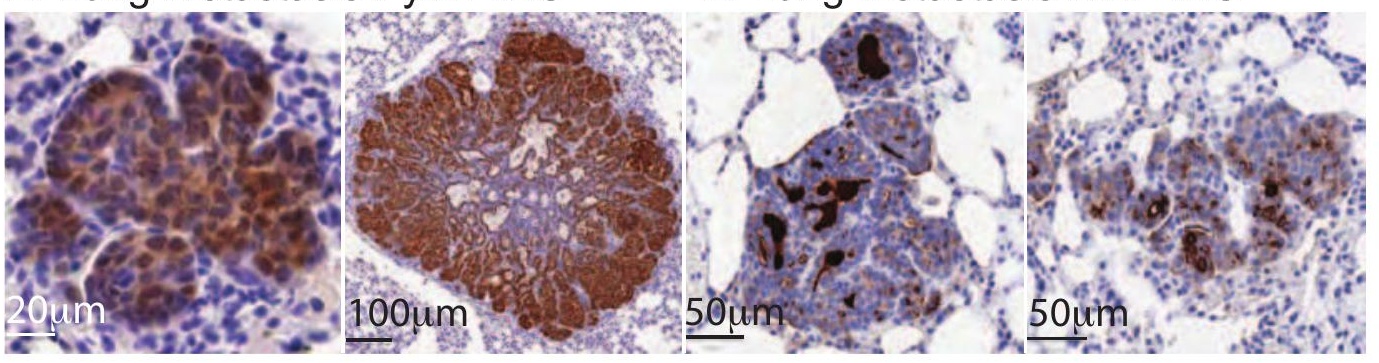


A. Phospho-Stat IHC

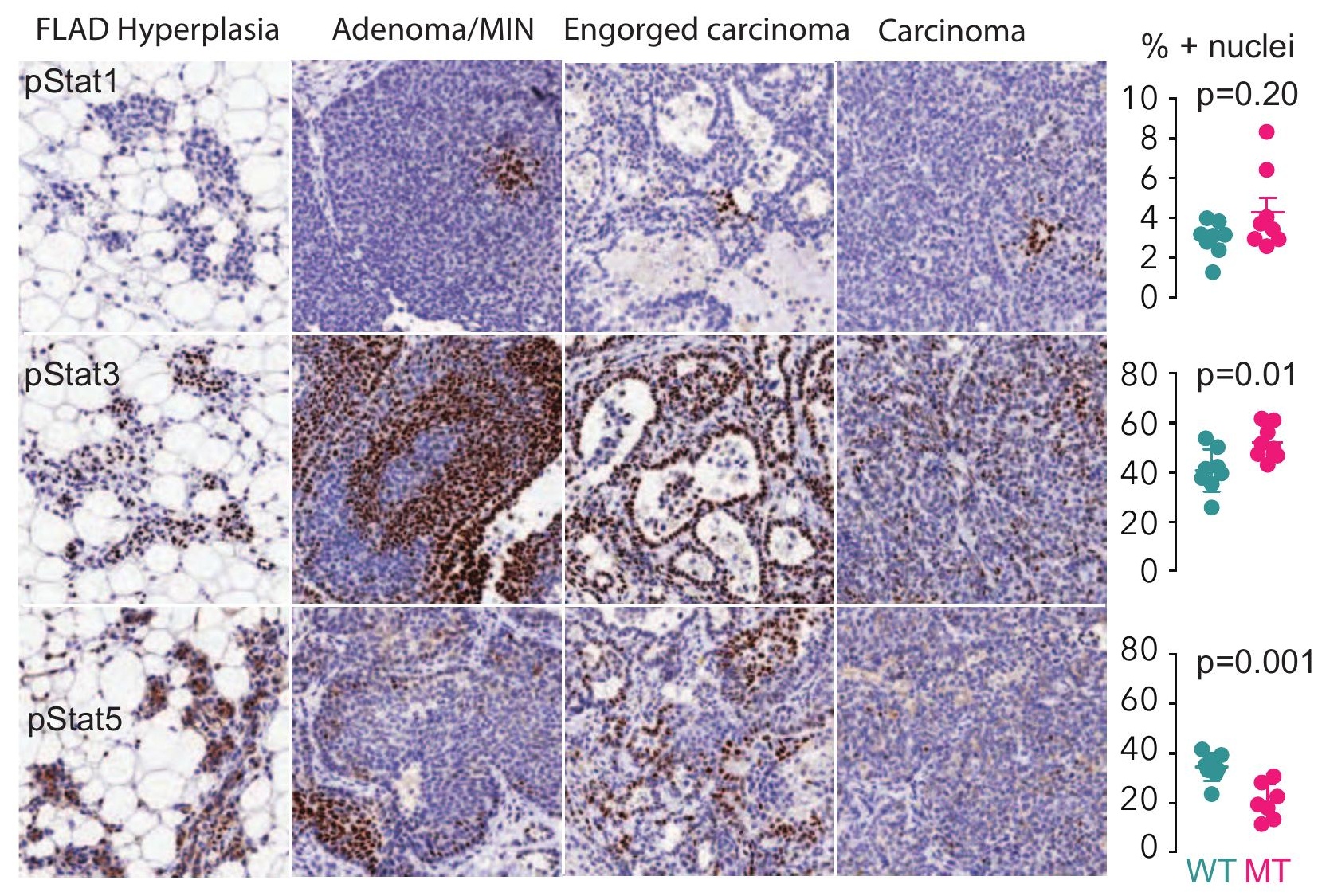

B. Cleaved caspase $3 \mathrm{IHC}$

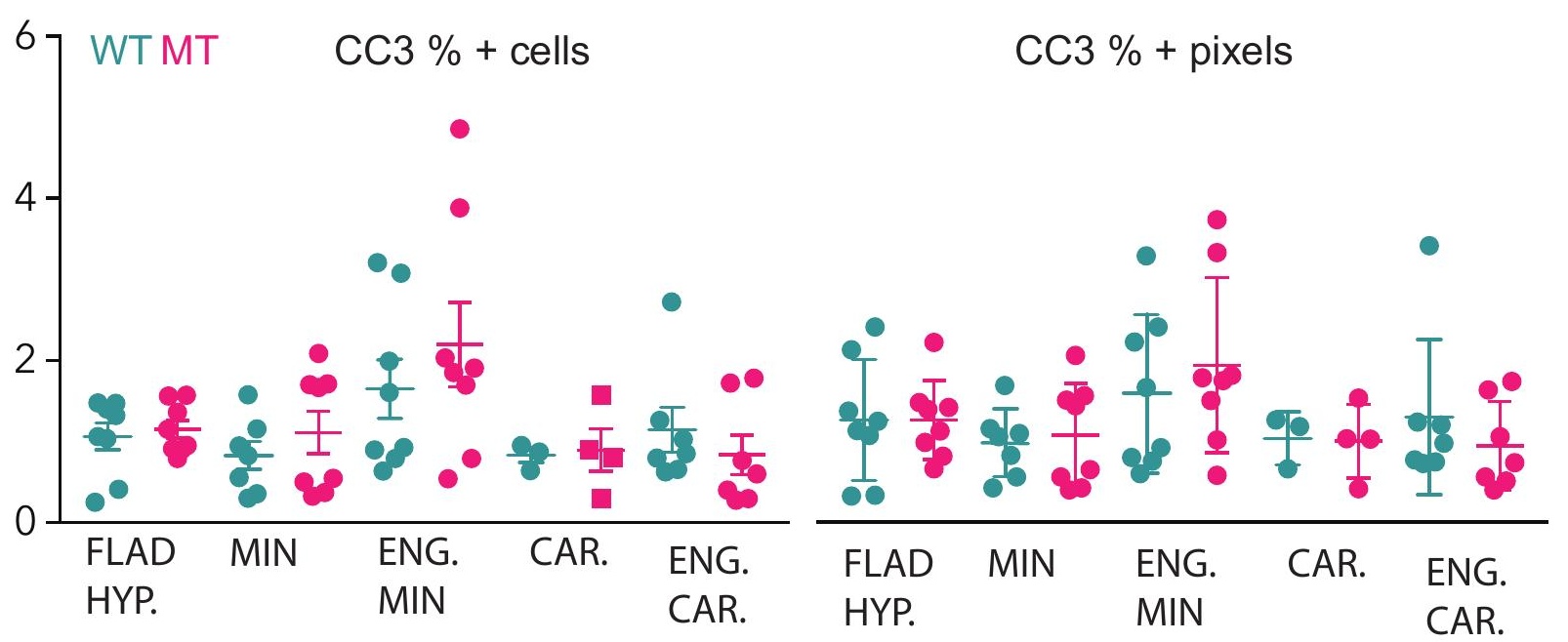


A. Age at Tumor Detection

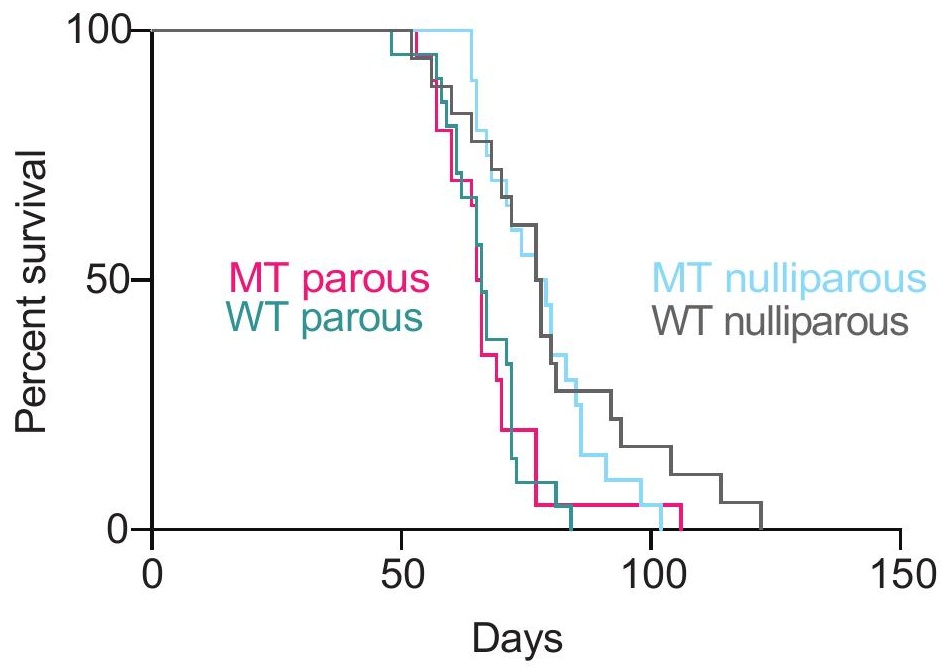

B. Time from Detection to Ethical Endpoint

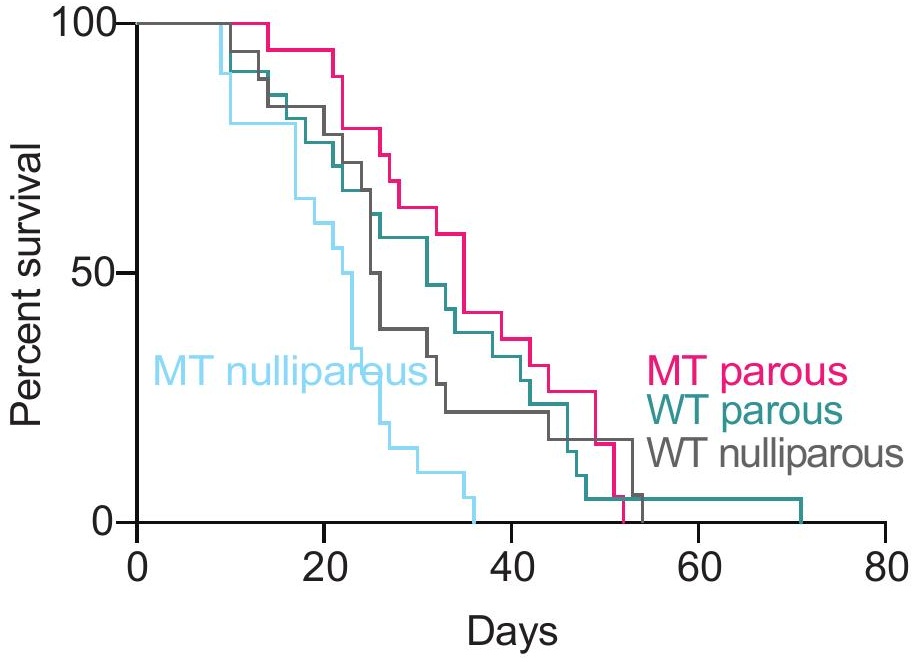

C. Age at Ethical Endpoint

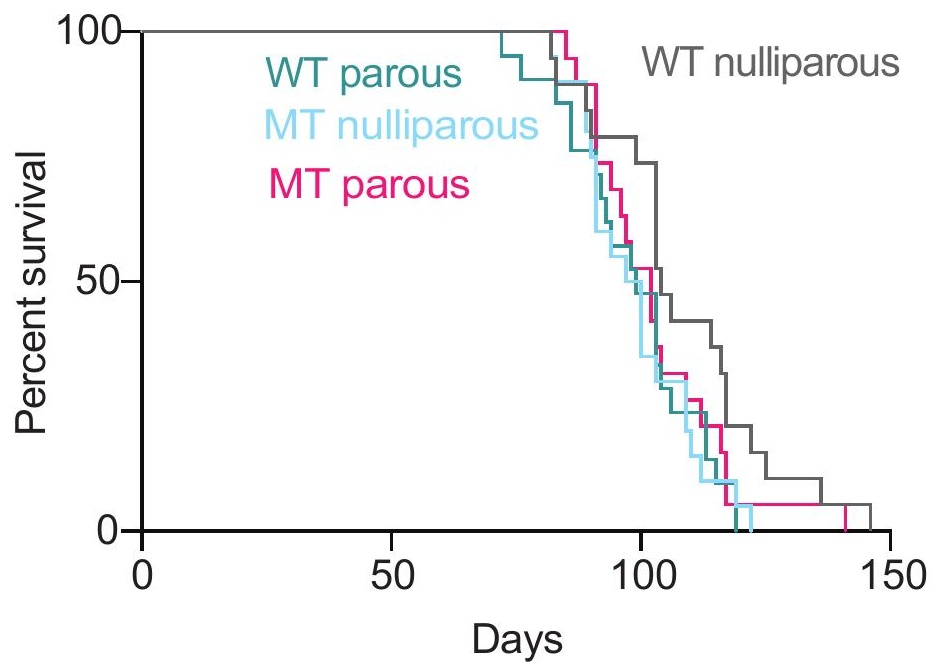

Ho et al. Figure 3. 
A. Tumour \% Body Weight at Ethical Endpoint

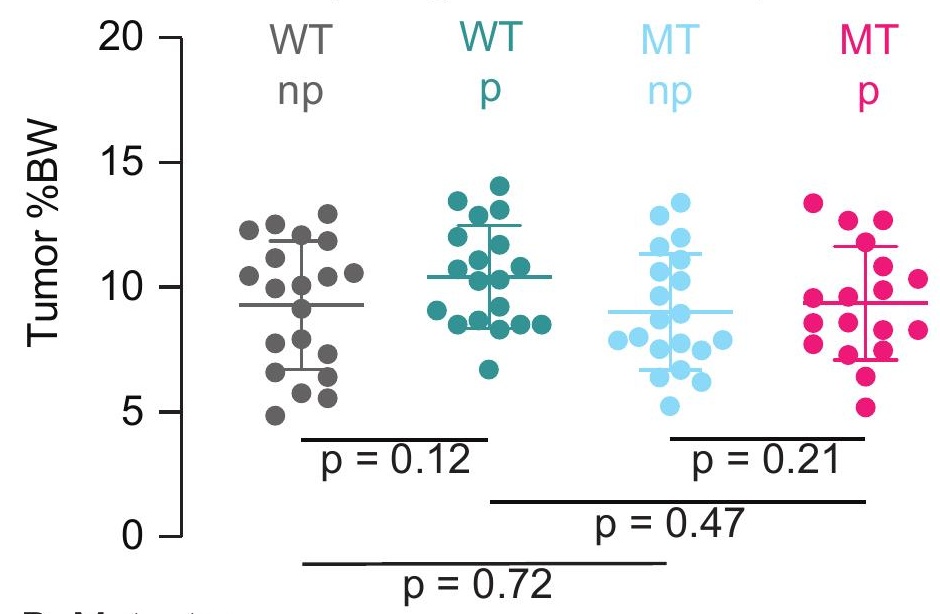

B. Metastases
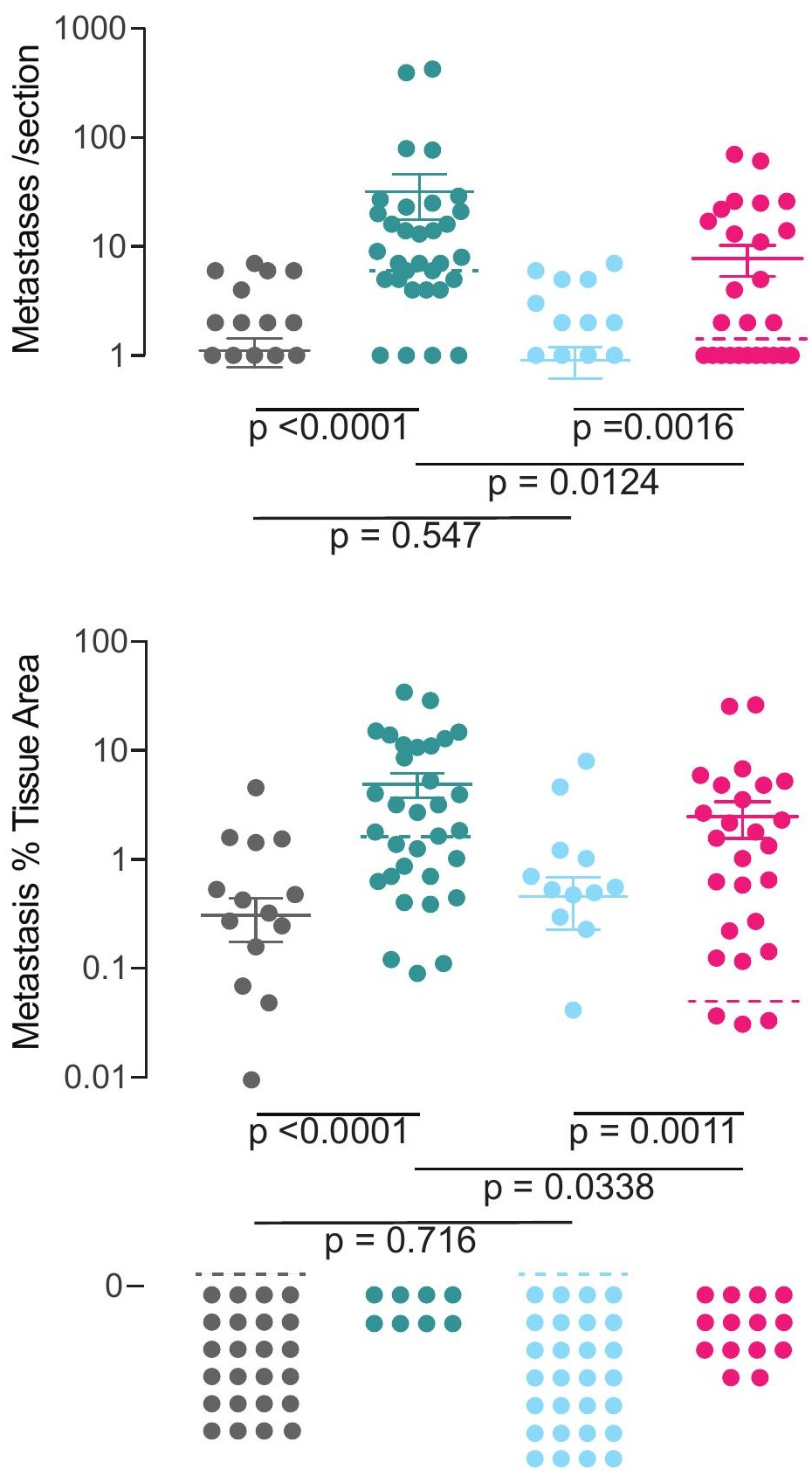

Ho et al. Figure 4. 


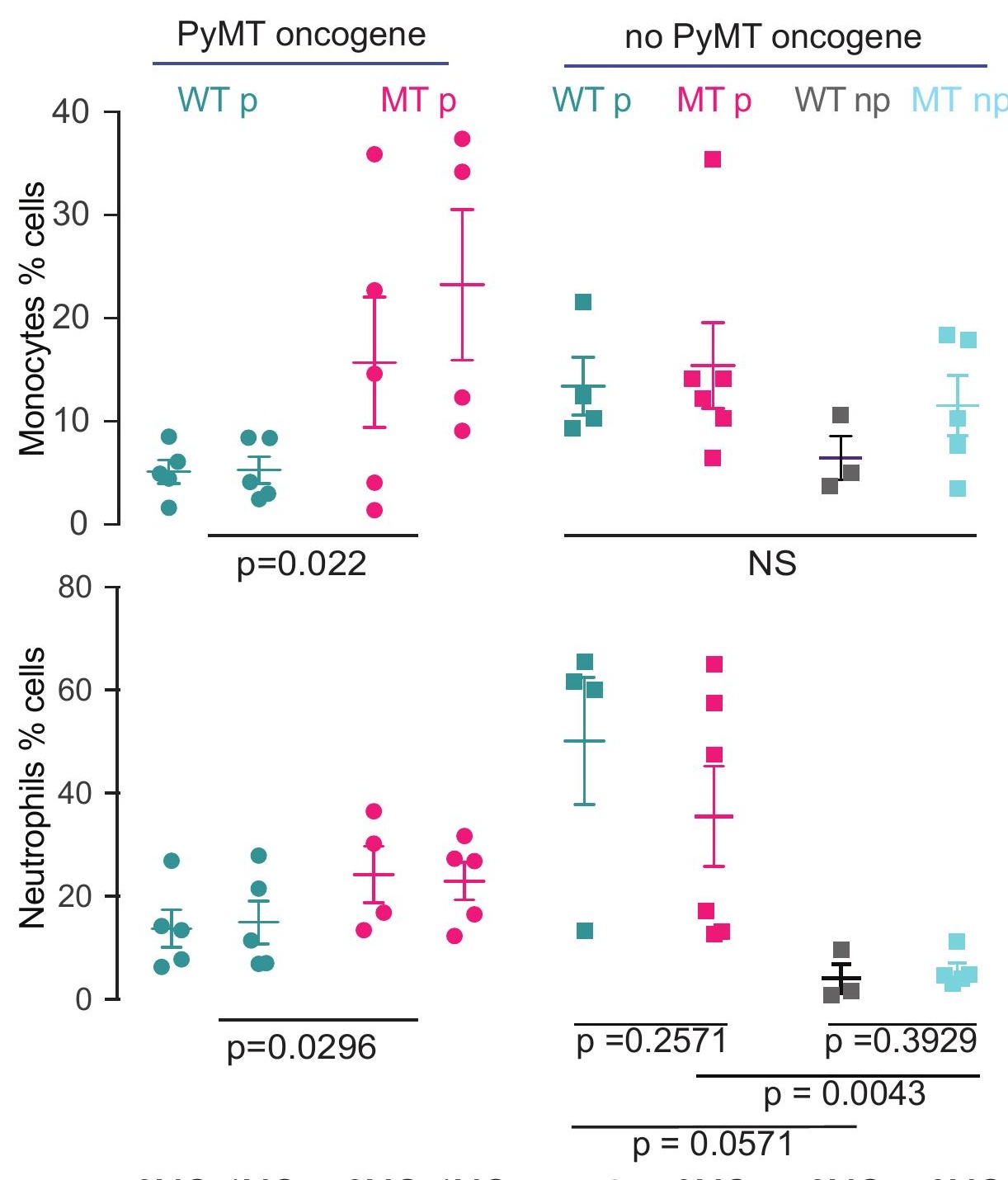

3MG 4MG 3MG 4MG 3MG 3MG 3MG 3MG 
A. Age at Tumor Detection

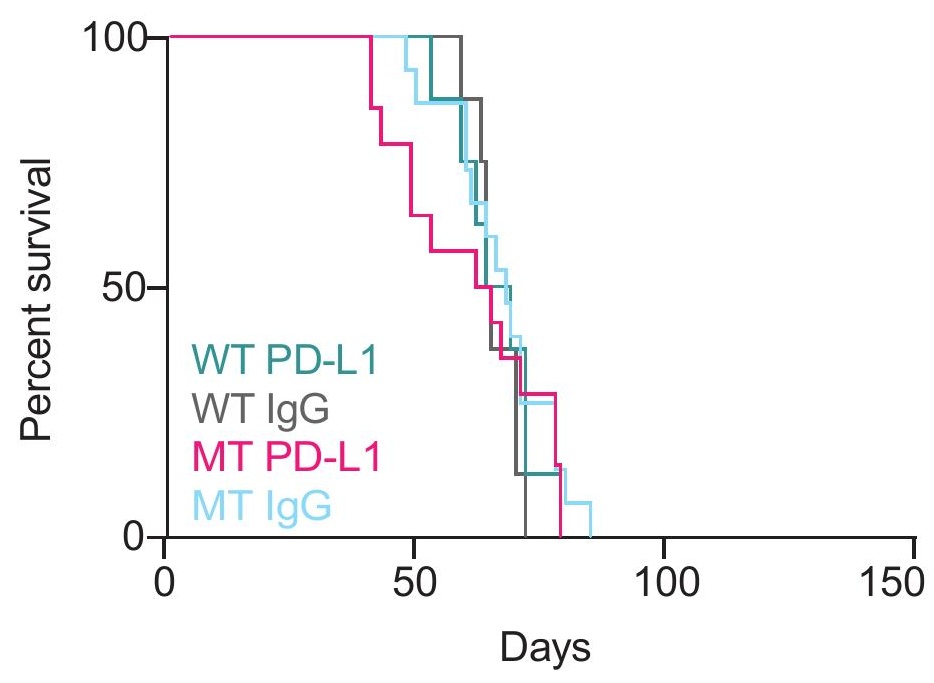

B. Time from Detection to Ethical Endpoint

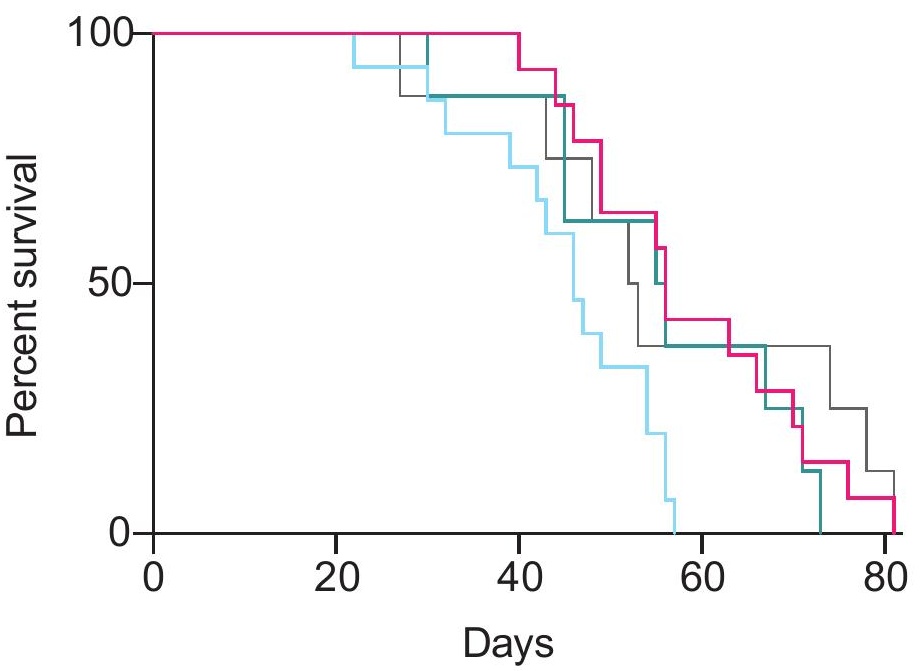

C. Age at Ethical Endpoint

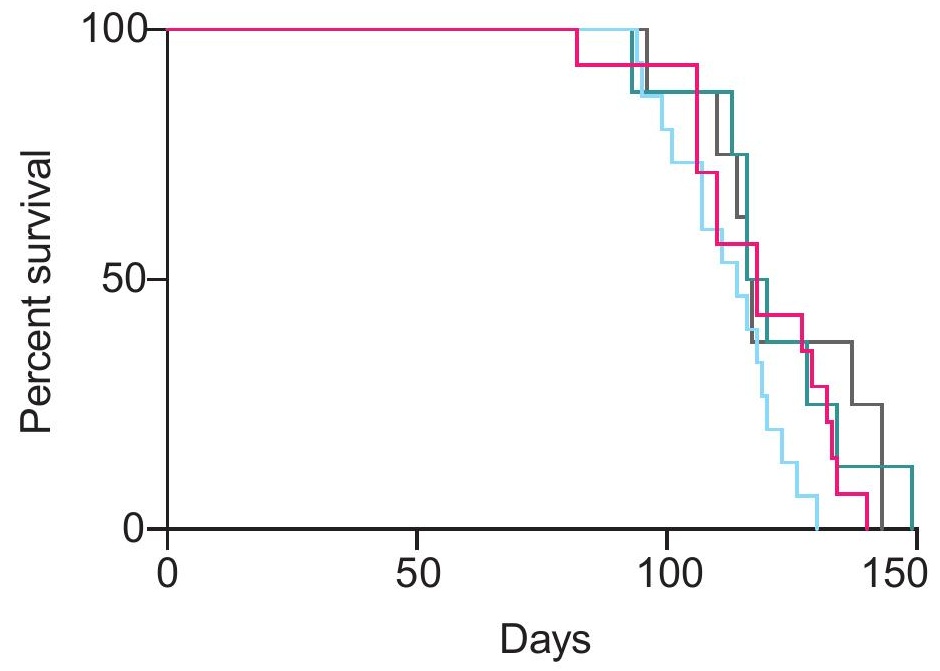

Ho et al. Figure 6. 
A. Tumour \% Body Weight at Ethical Endpoint

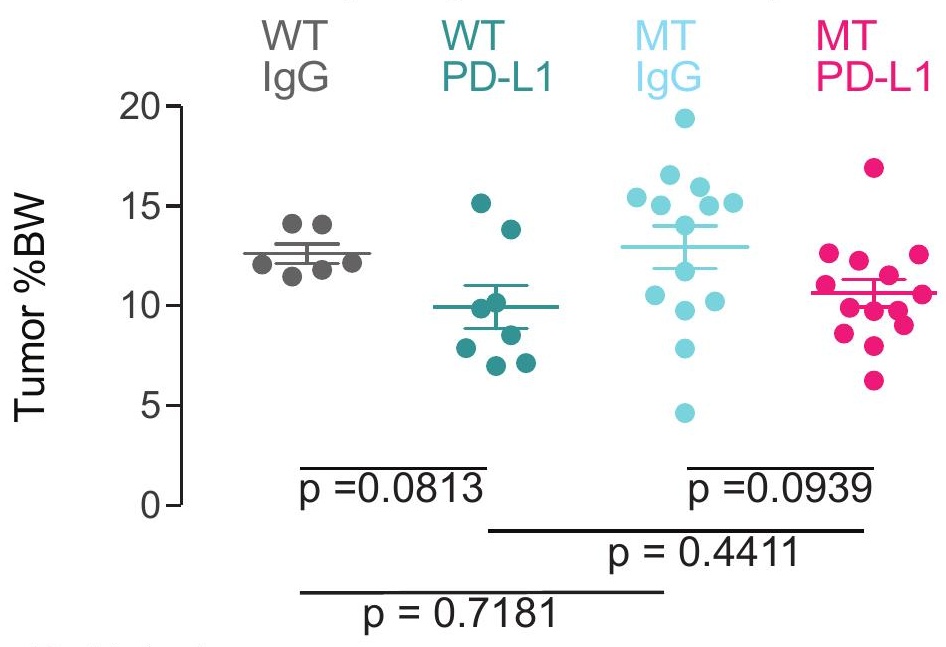

B. Metastases
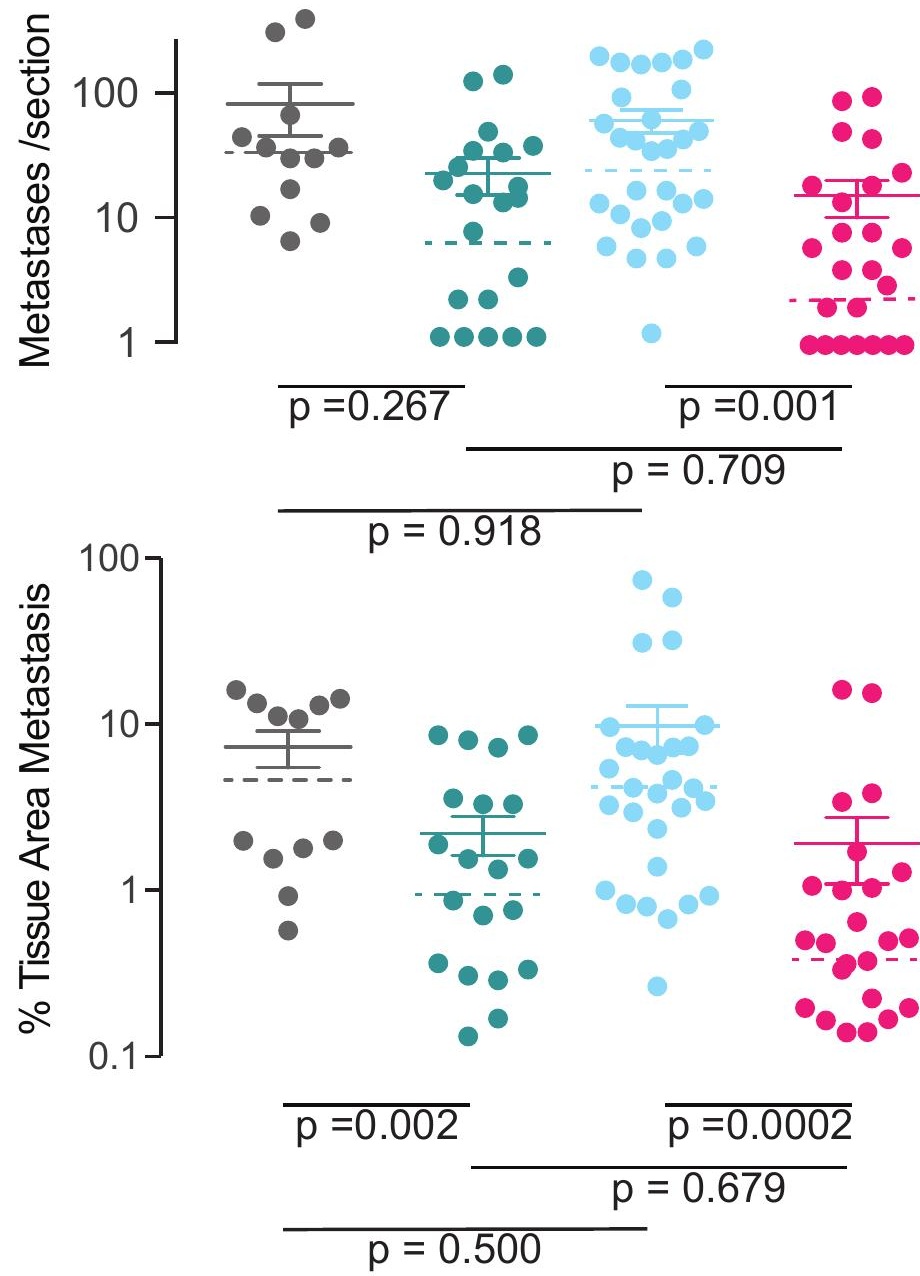

$0-$
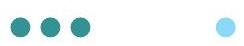

Ho et al. Figure 7. 
A. Mammary Gland \% Body Weight at d15pp

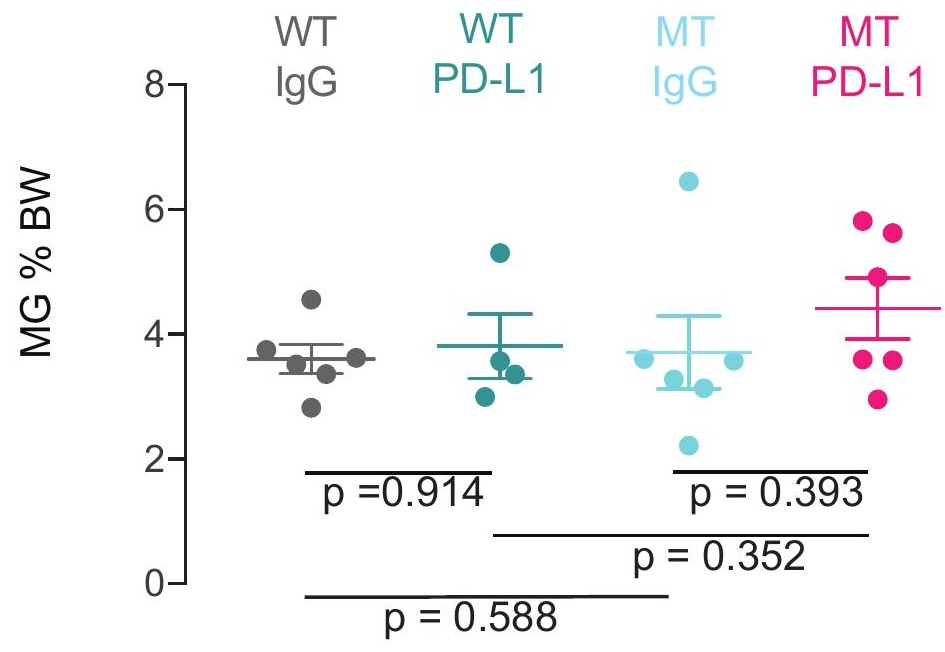

B. Metastases

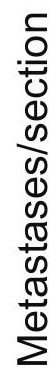
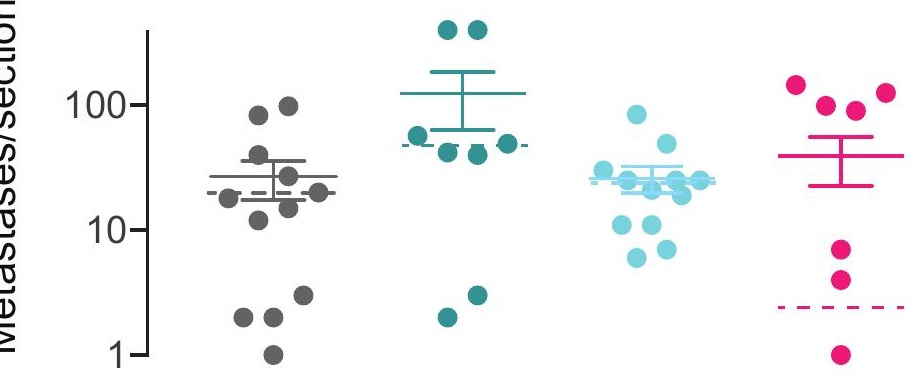

$$
\begin{gathered}
\mathrm{p=0.109} \quad \frac{p=0.200}{p=0.128} \\
\cline { 2 - 2 }
\end{gathered}
$$

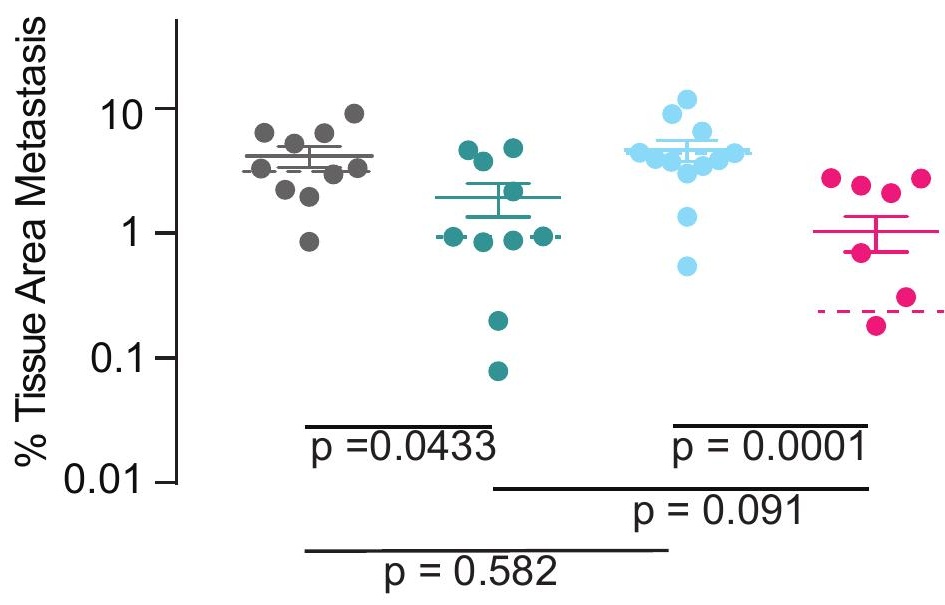

0-

Ho et al. Figure 8. 


\begin{tabular}{|c|c|c|c|c|c|}
\hline n tumours & $\begin{array}{l}\text { Period of } \\
\text { no growth }\end{array}$ & $\begin{array}{l}\text { Tumour } \\
\text { reqression }\end{array}$ & $\mathrm{n}$ tumours & $\begin{array}{l}\text { Period of } \\
\text { no growth }\end{array}$ & $\begin{array}{l}\text { Tumour } \\
\text { regression }\end{array}$ \\
\hline
\end{tabular}
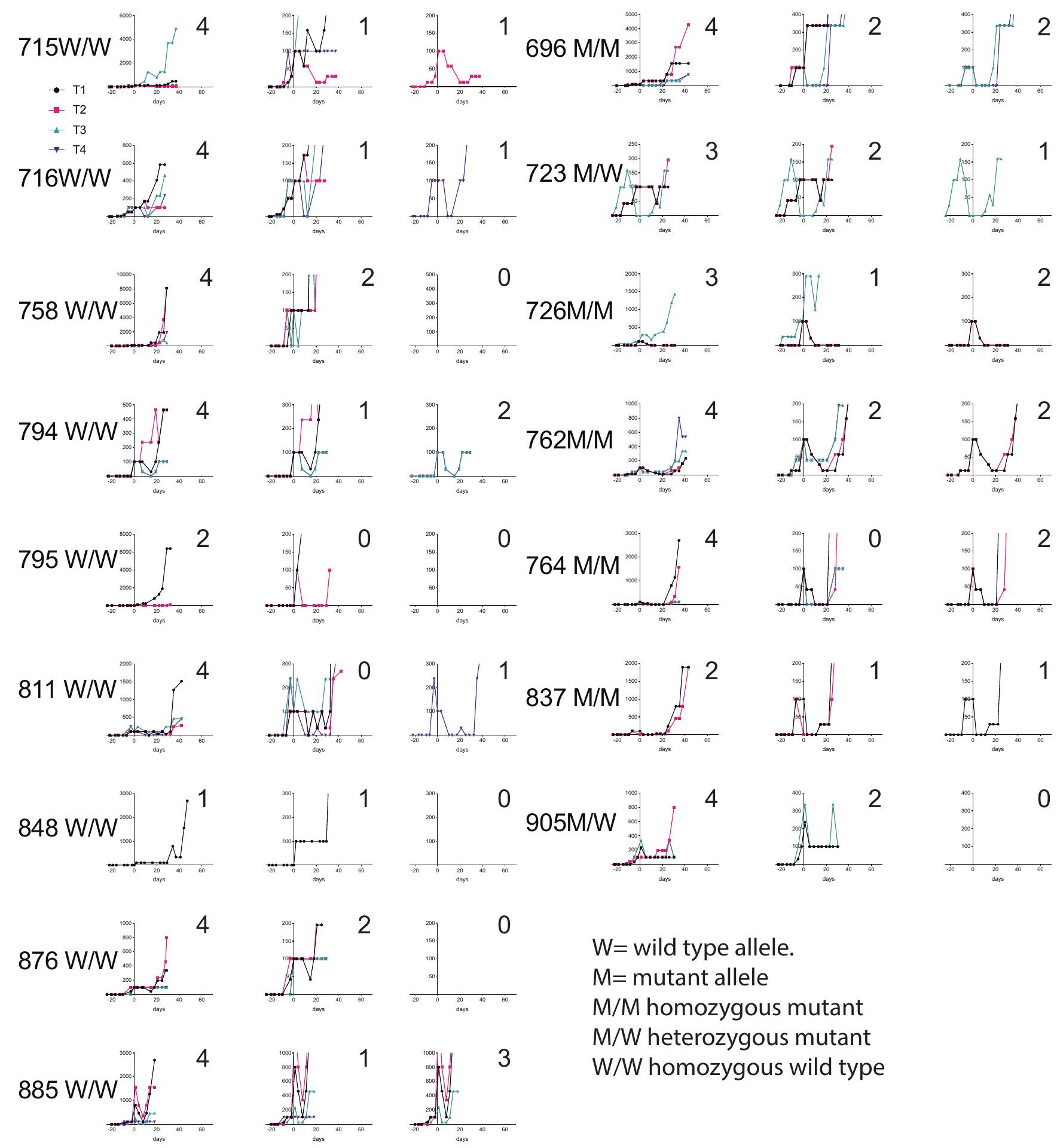

$\mathrm{W}=$ wild type allele.

$\mathrm{M}=$ mutant allele

$\mathrm{M} / \mathrm{M}$ homozygous mutant

$\mathrm{M} / \mathrm{W}$ heterozygous mutant

W/W homozygous wild type
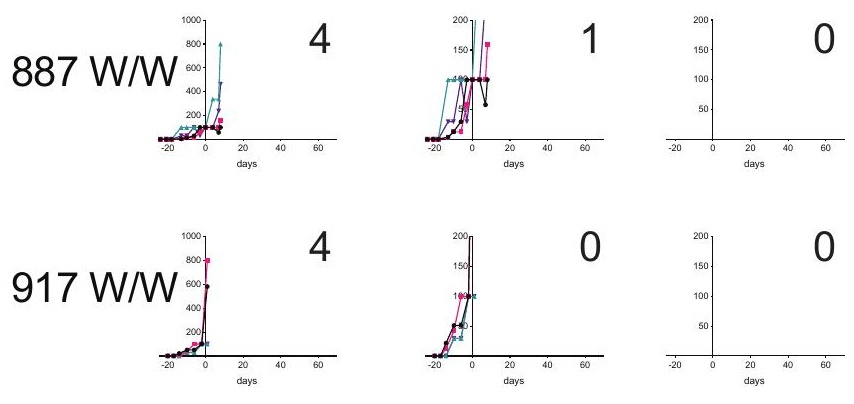

totals 39

$10(26 \%)$

$8(21 \%)$

totals $24 \quad 10(42 \%)$

$10(42 \%)$

Ho et al. Supplementary Figure 1. 

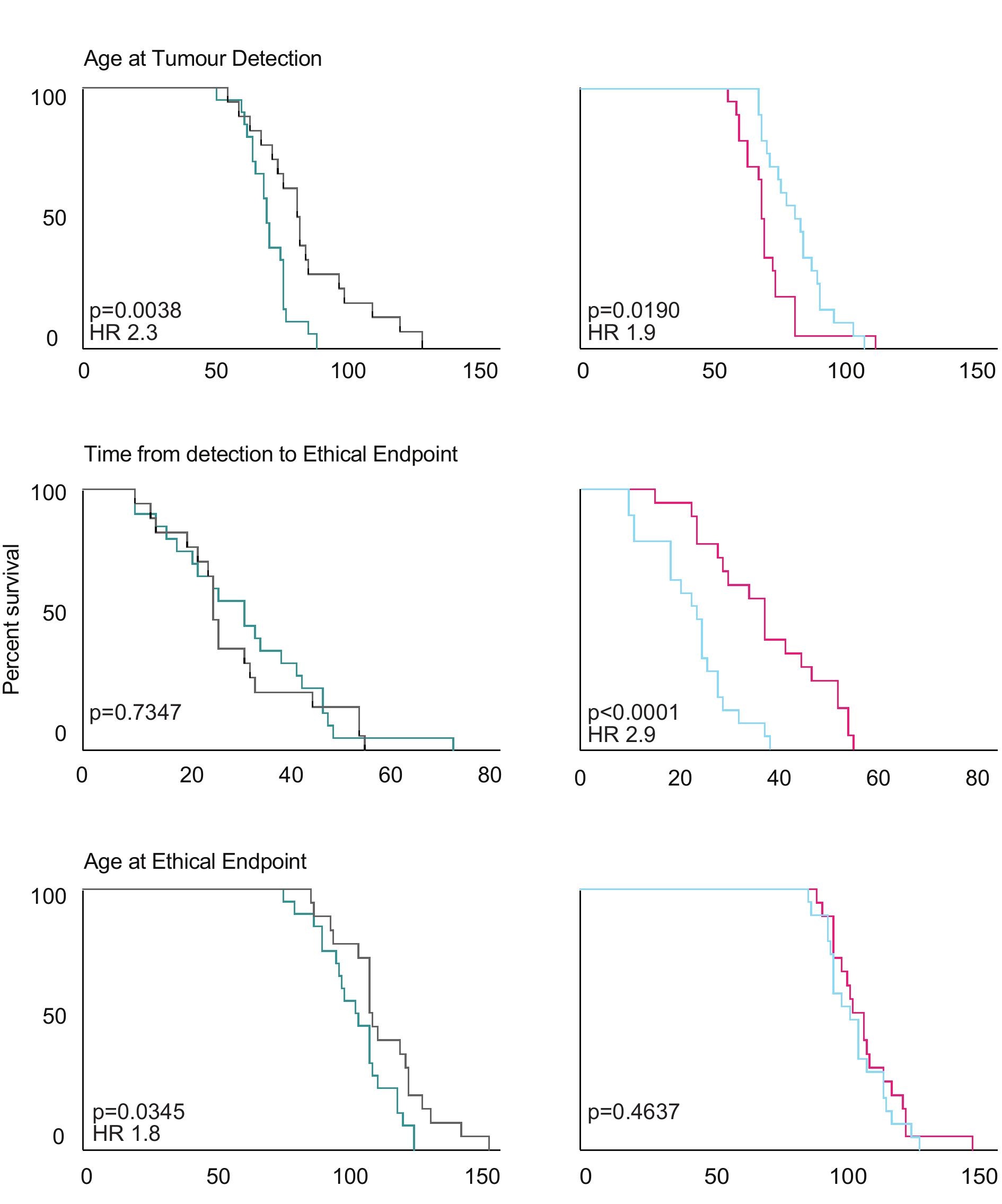

parous

WT
nulliparous

MT
parous
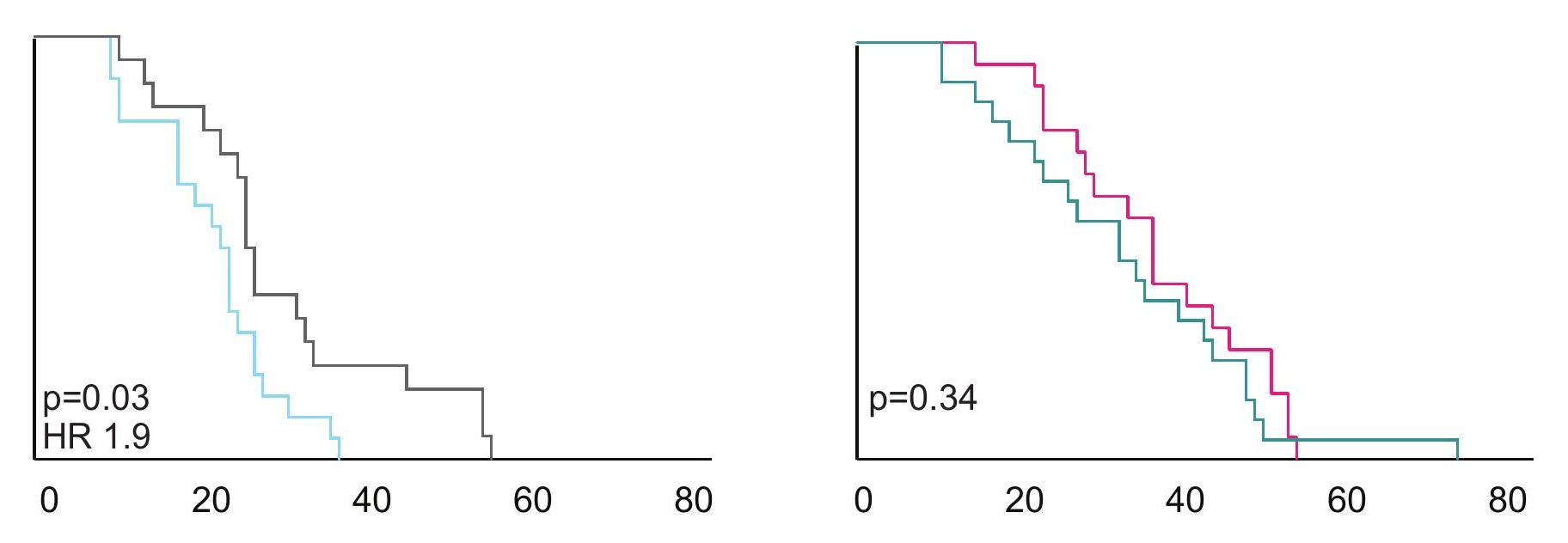

Days
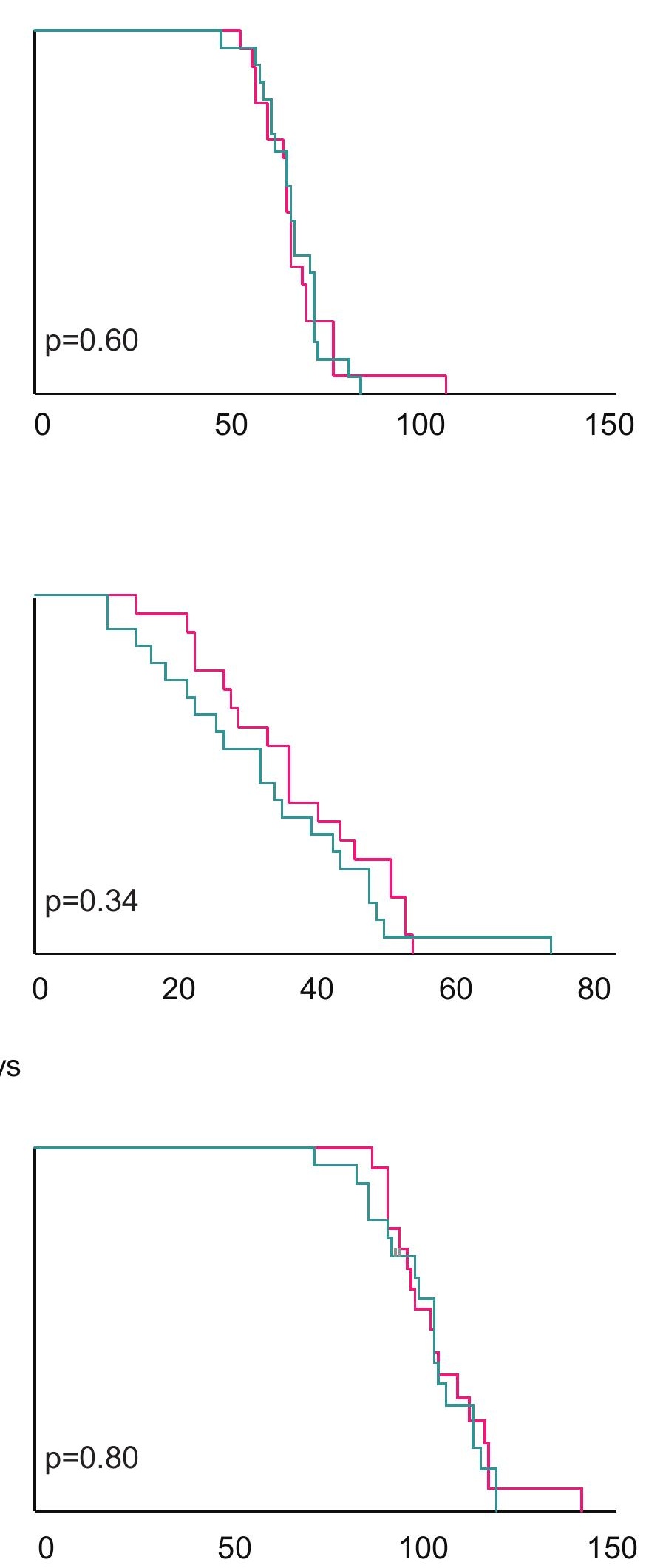
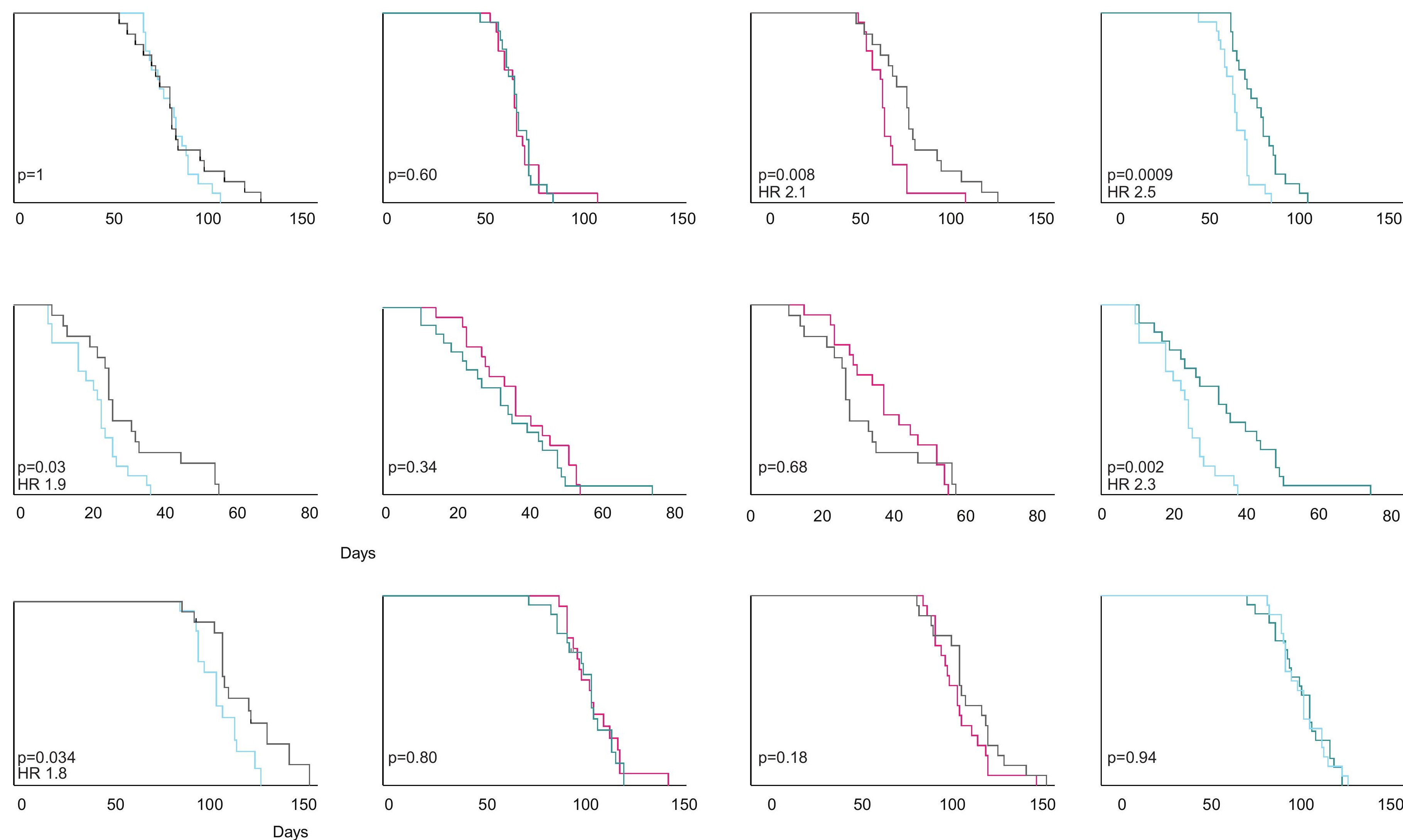

Ho et al. Supplementary Figure 2 . 

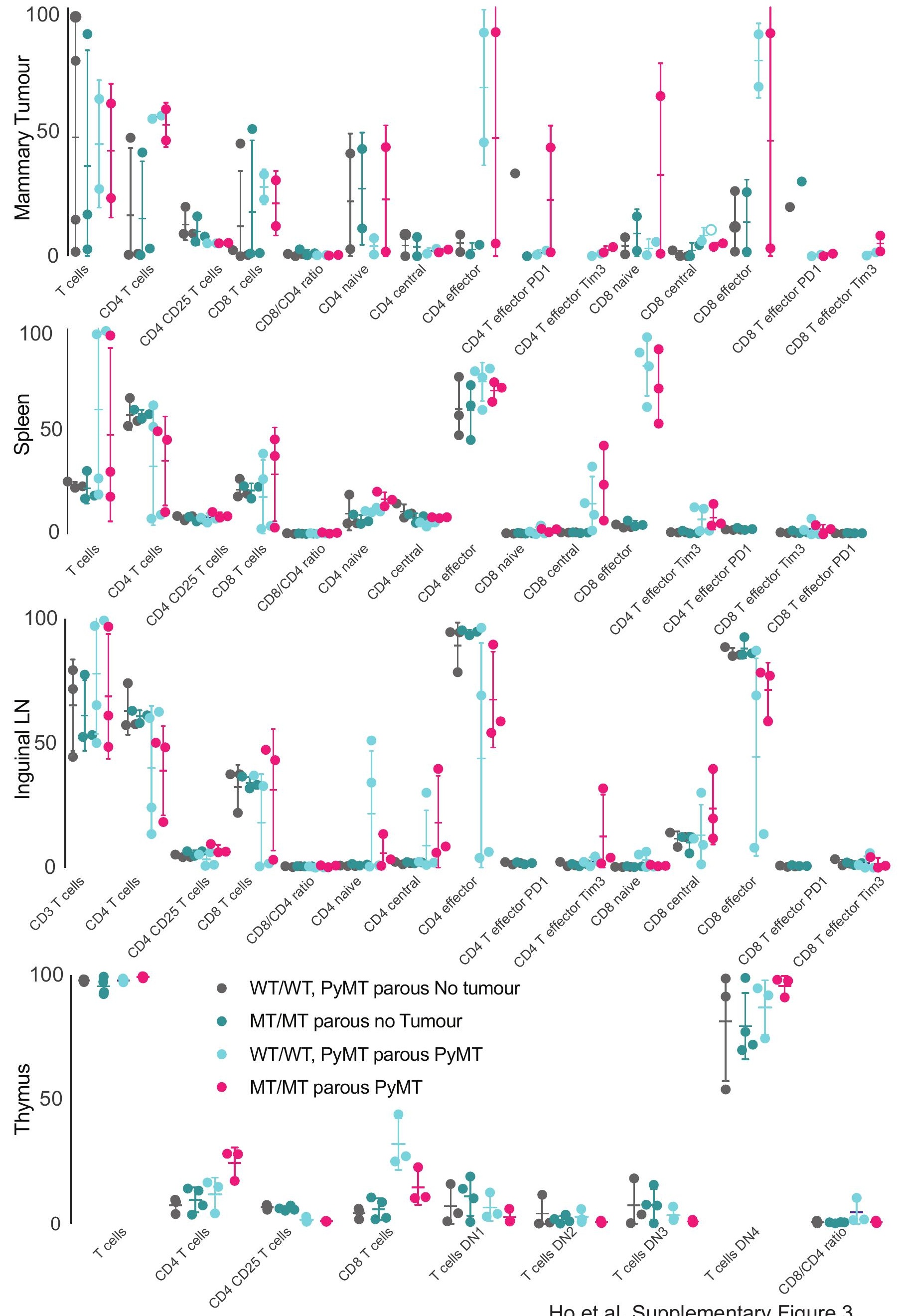

Ho et al. Supplementary Figure 3. 
Gating strategy monocytes and neutrophils (MDSC)
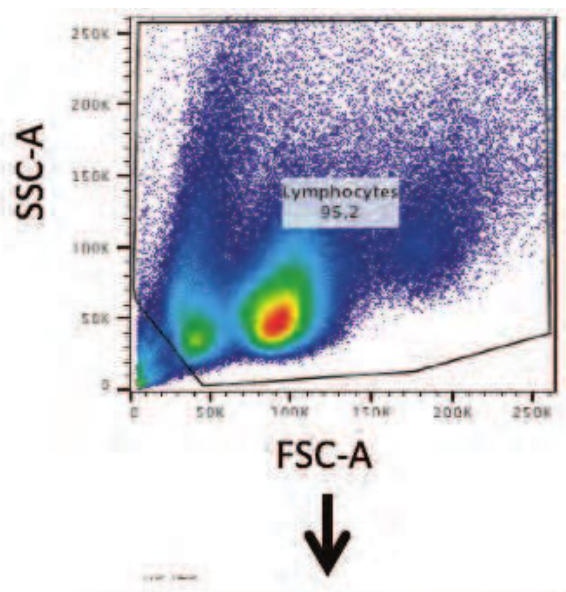

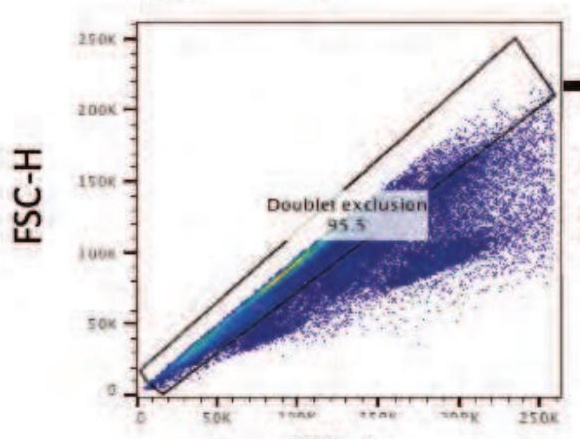

FSC-A

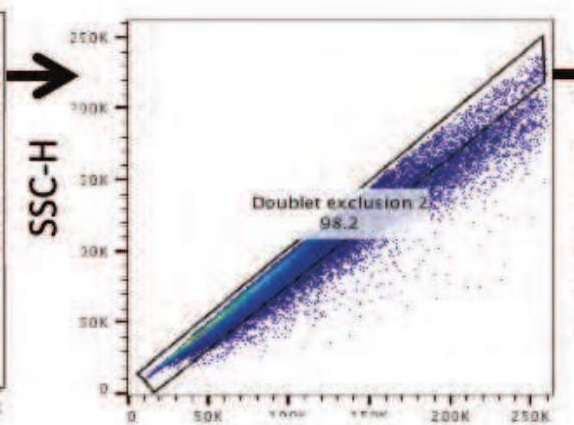

SSC-A

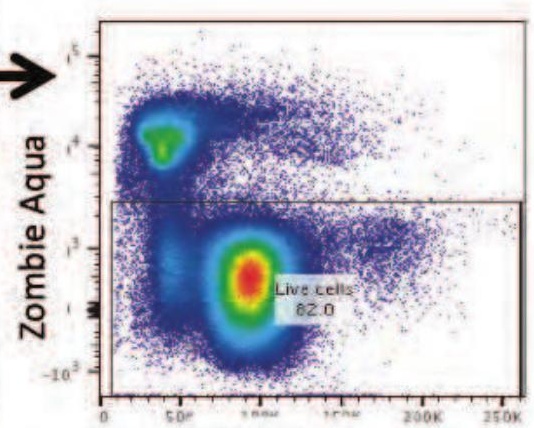

FSC-A

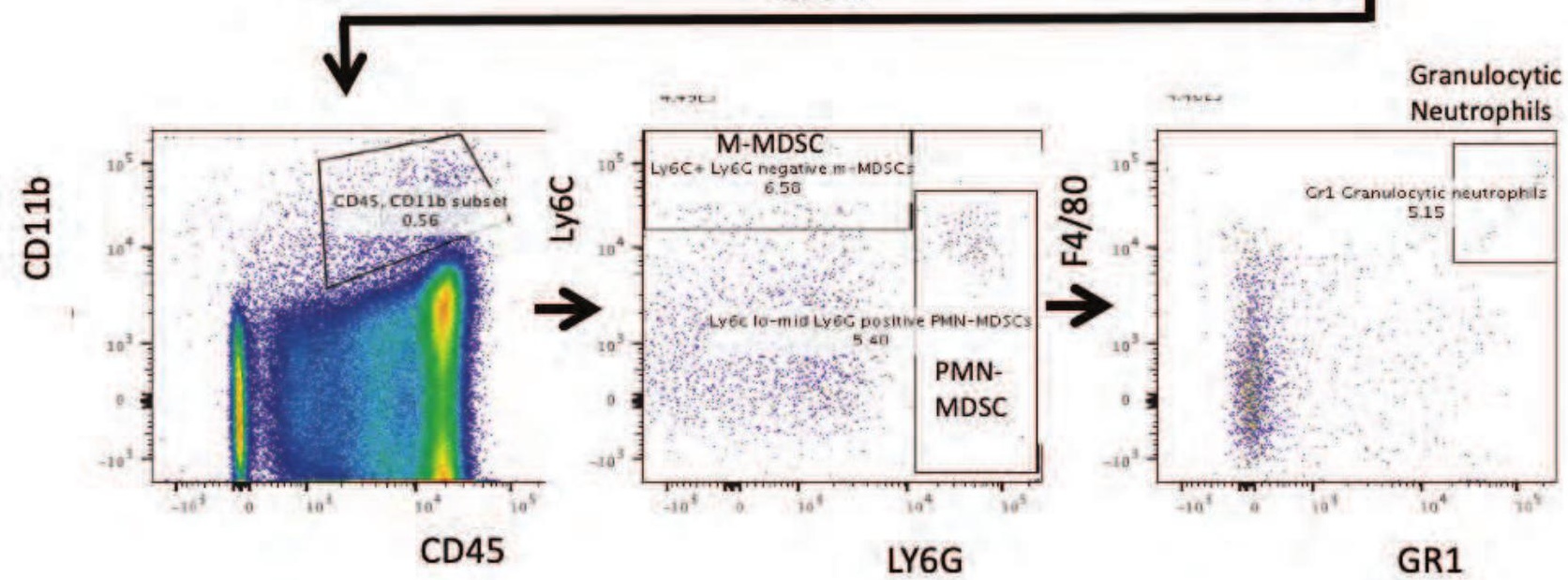


WT IgG

WT PD-L1

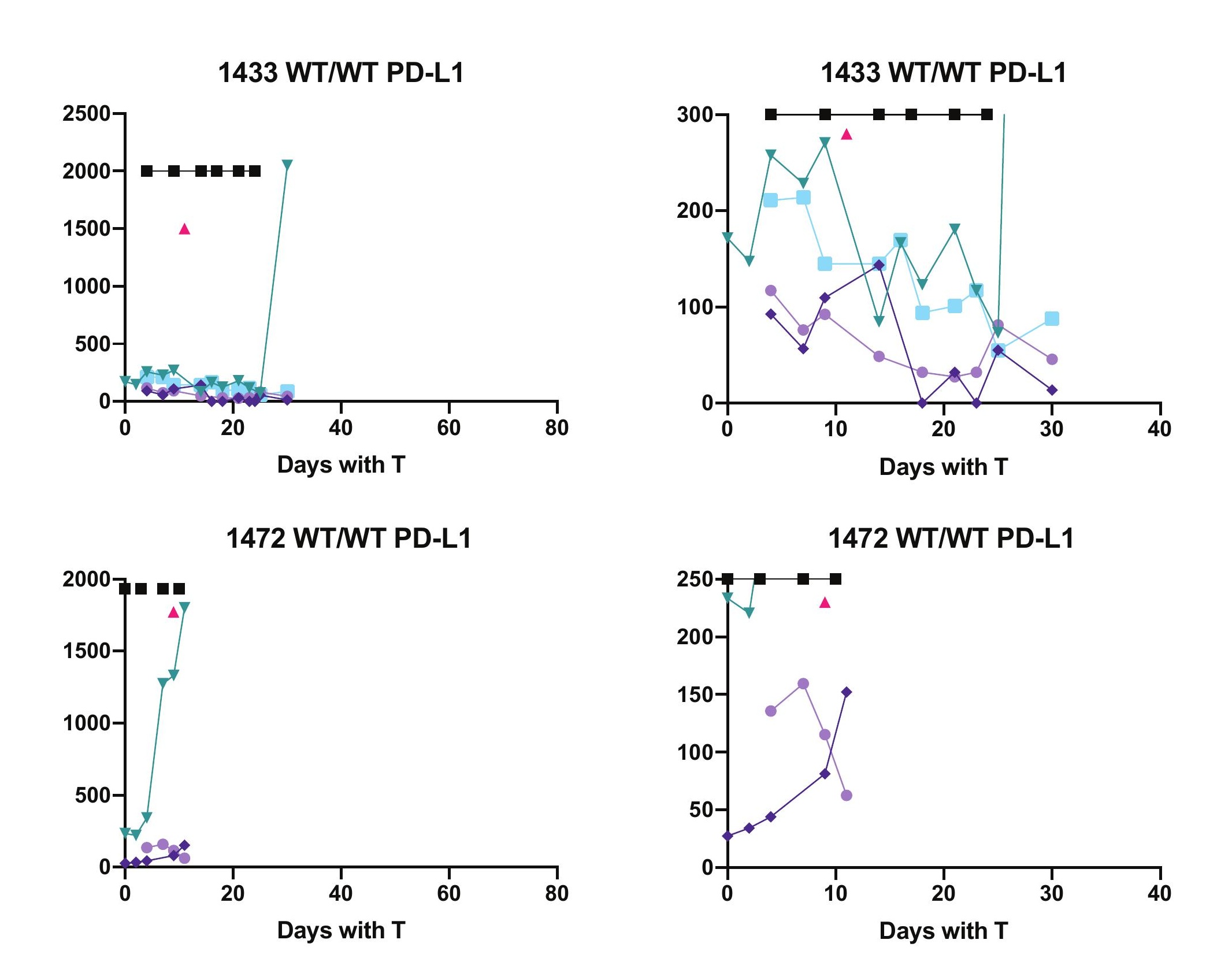

(15)

(1550 wTw P D.11
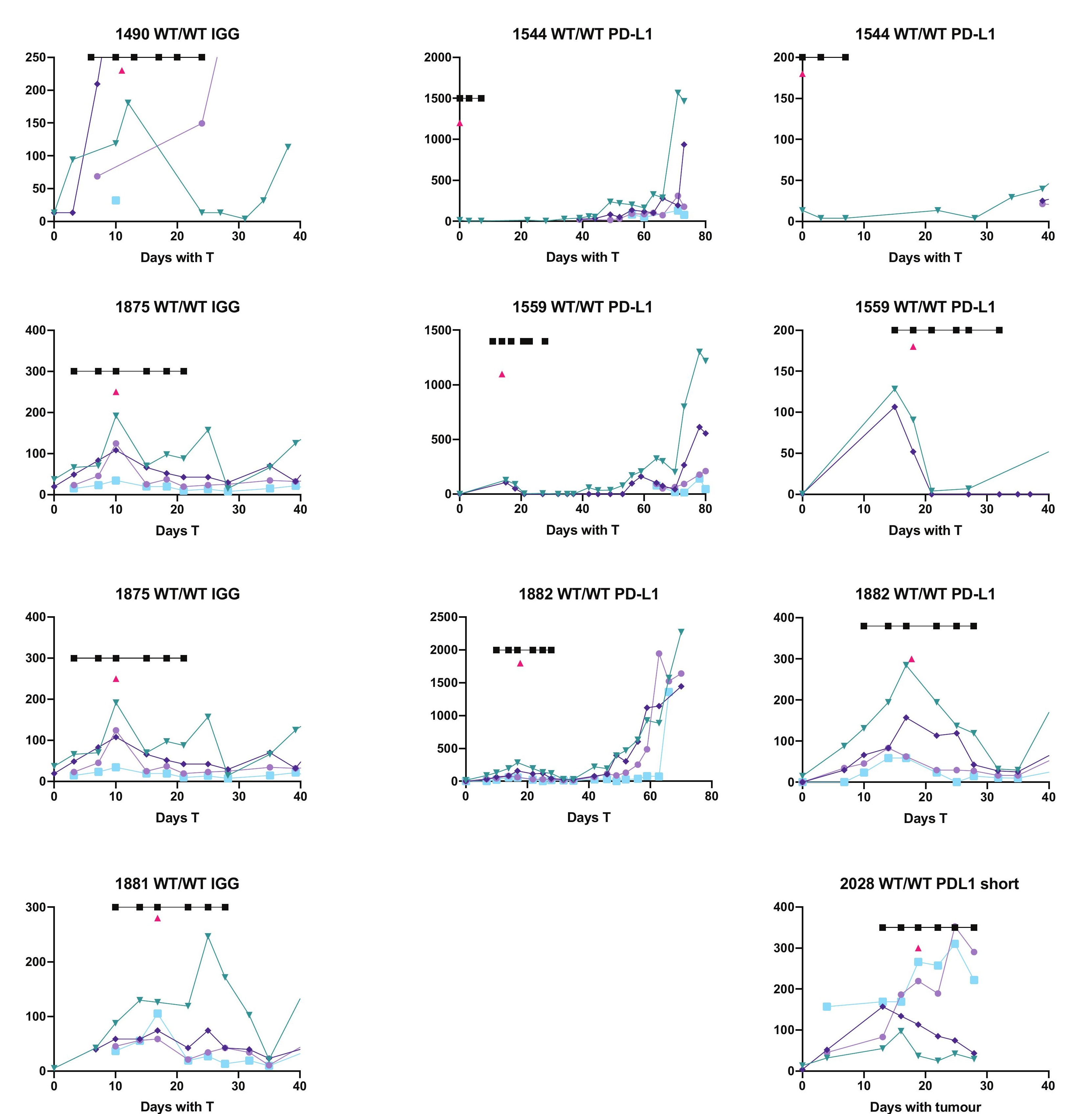

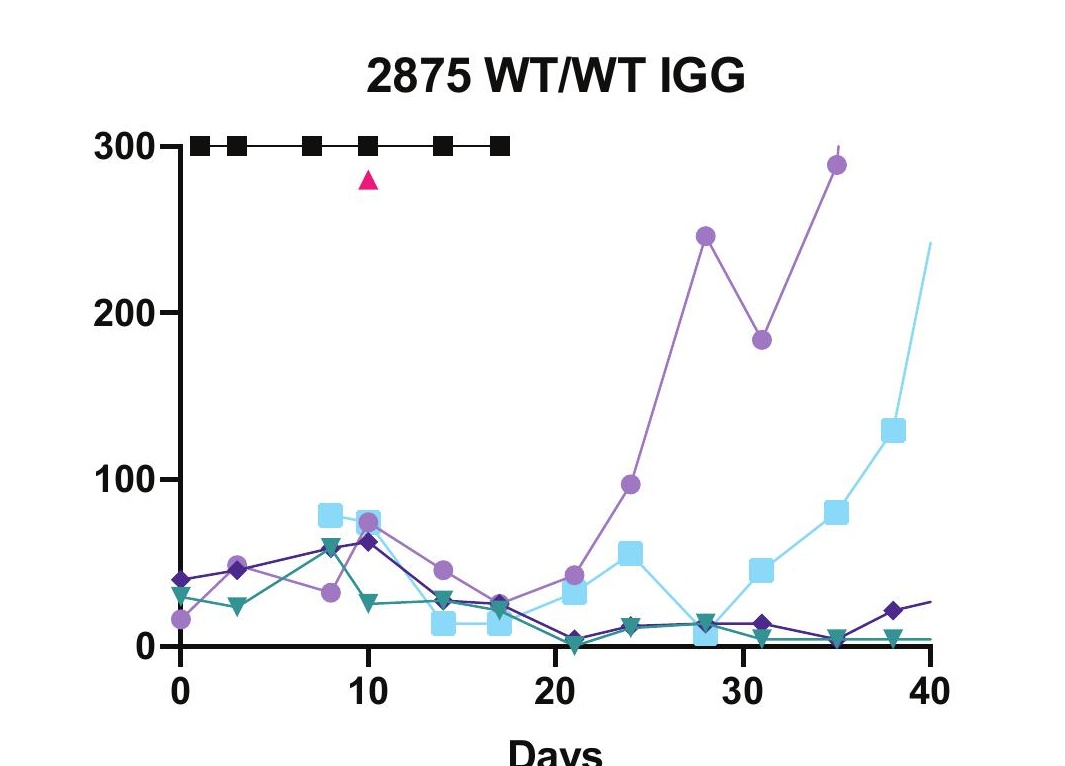
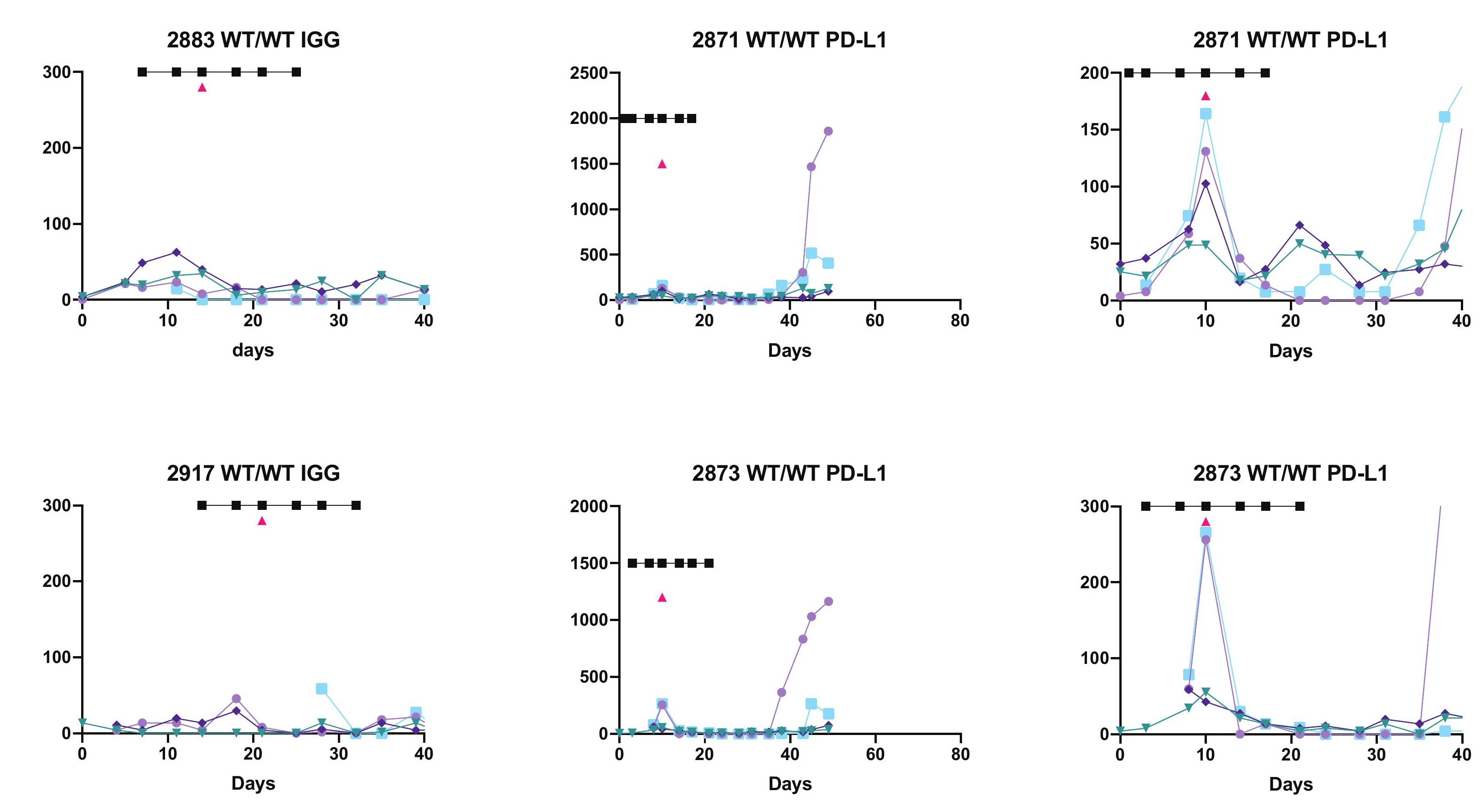

(1)

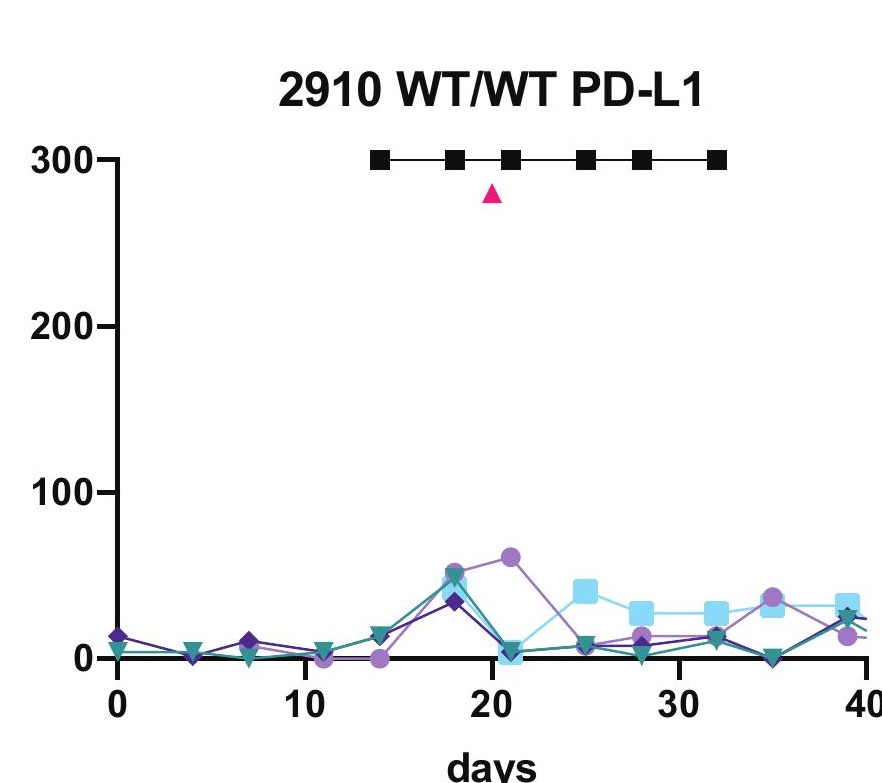

MT/MT IgG
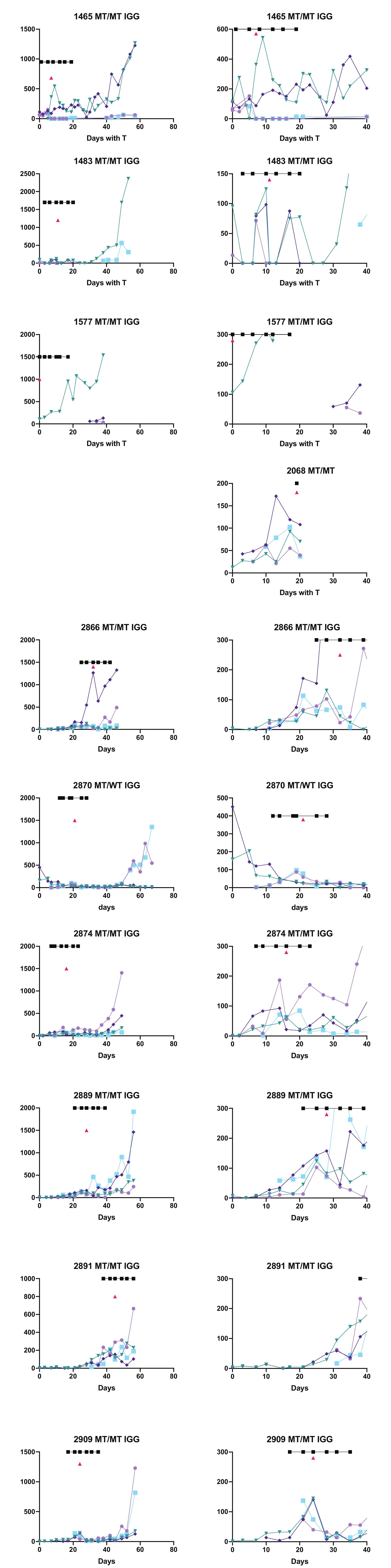

\section{MT/WT IgG}
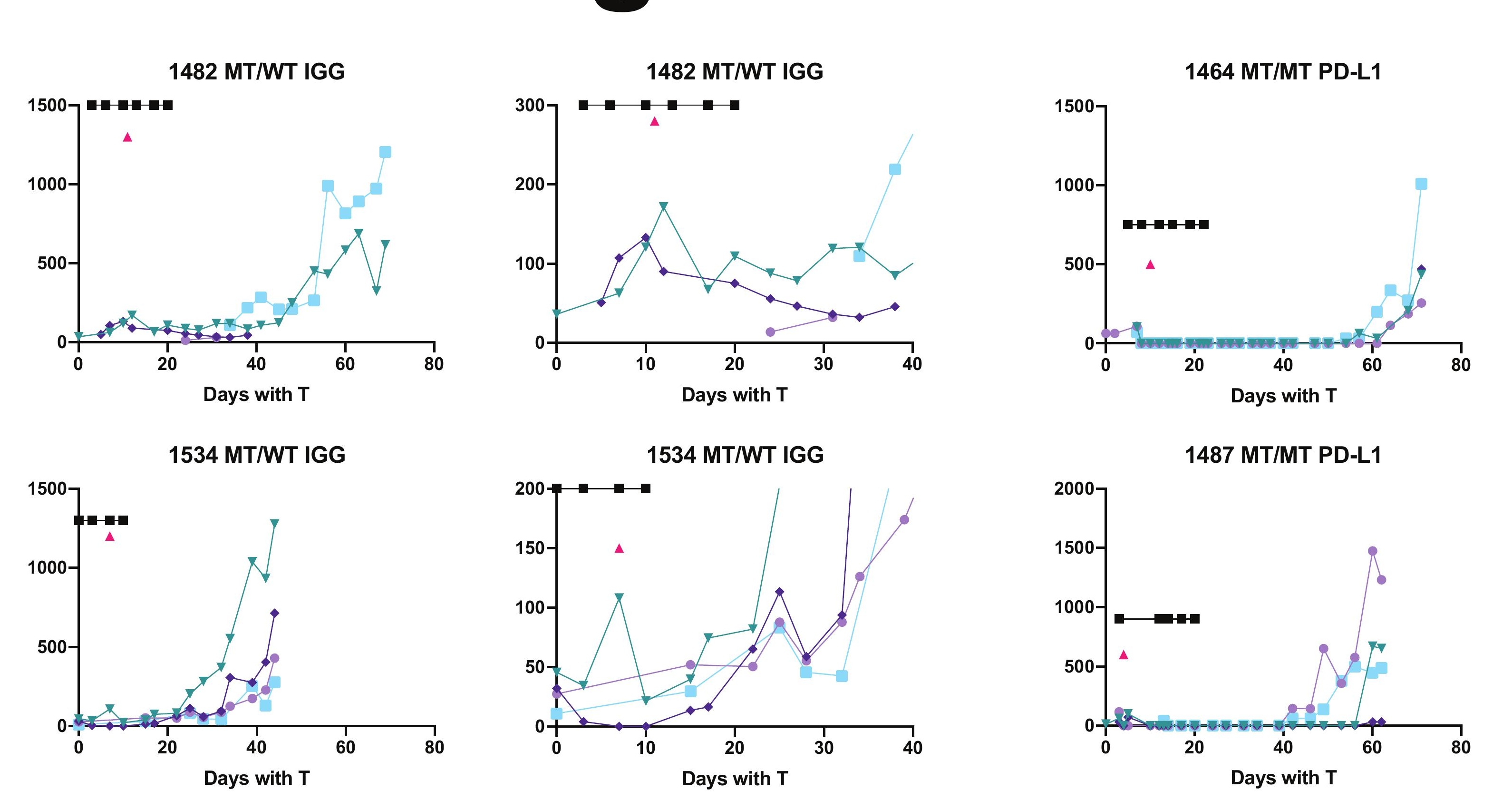

D.
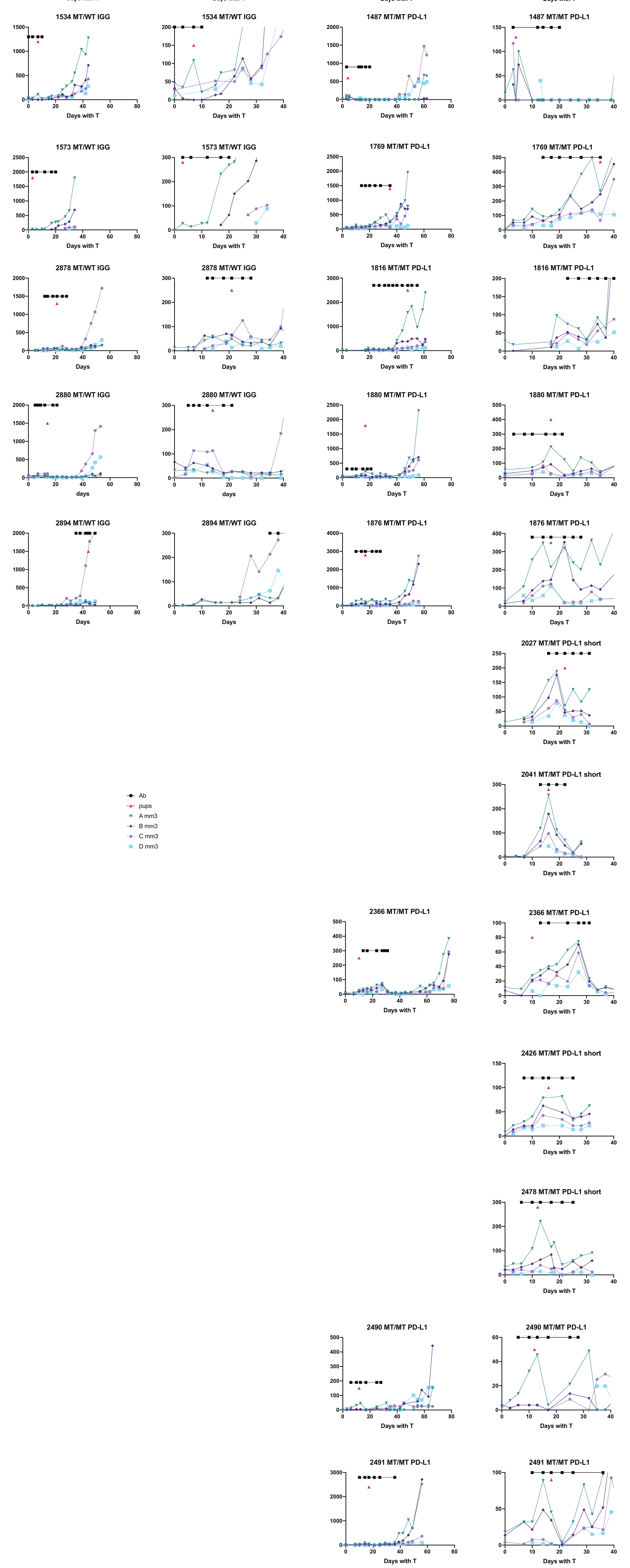

2500
2000
1500
2000
500
50
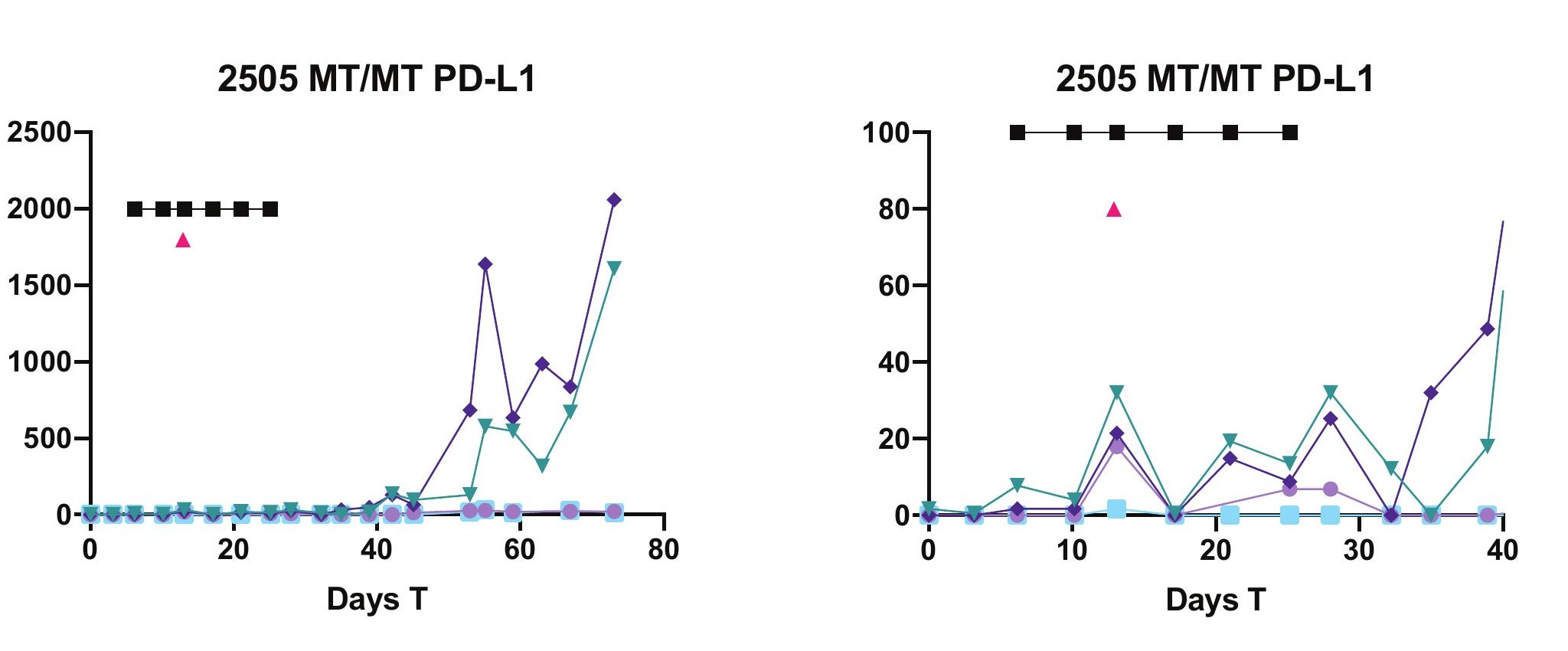

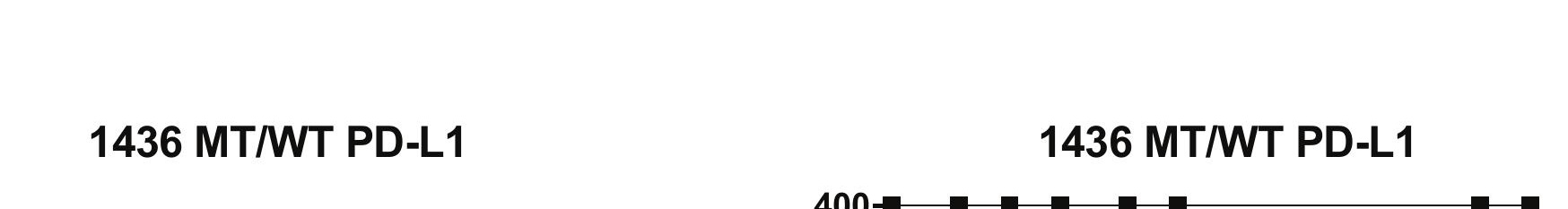
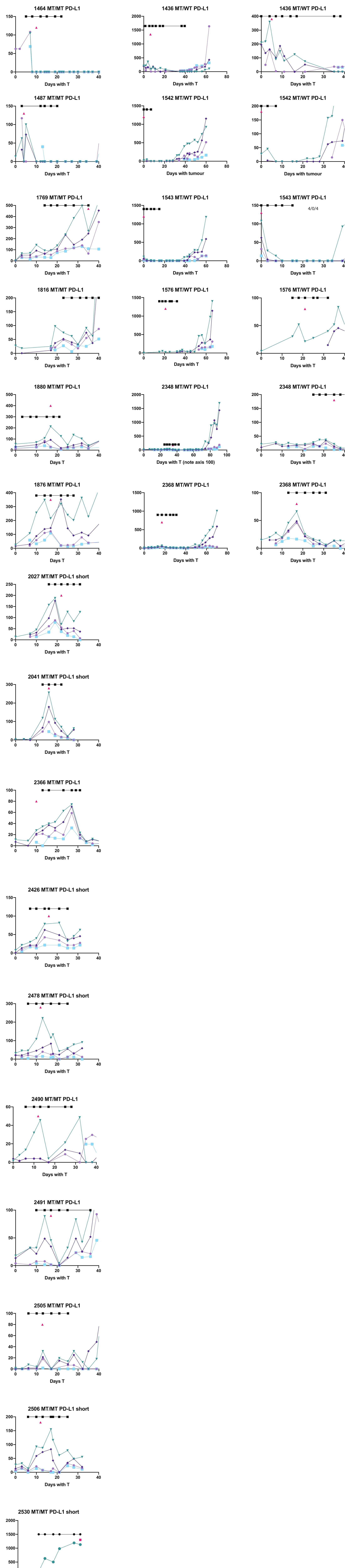
Age at Tumour Detection
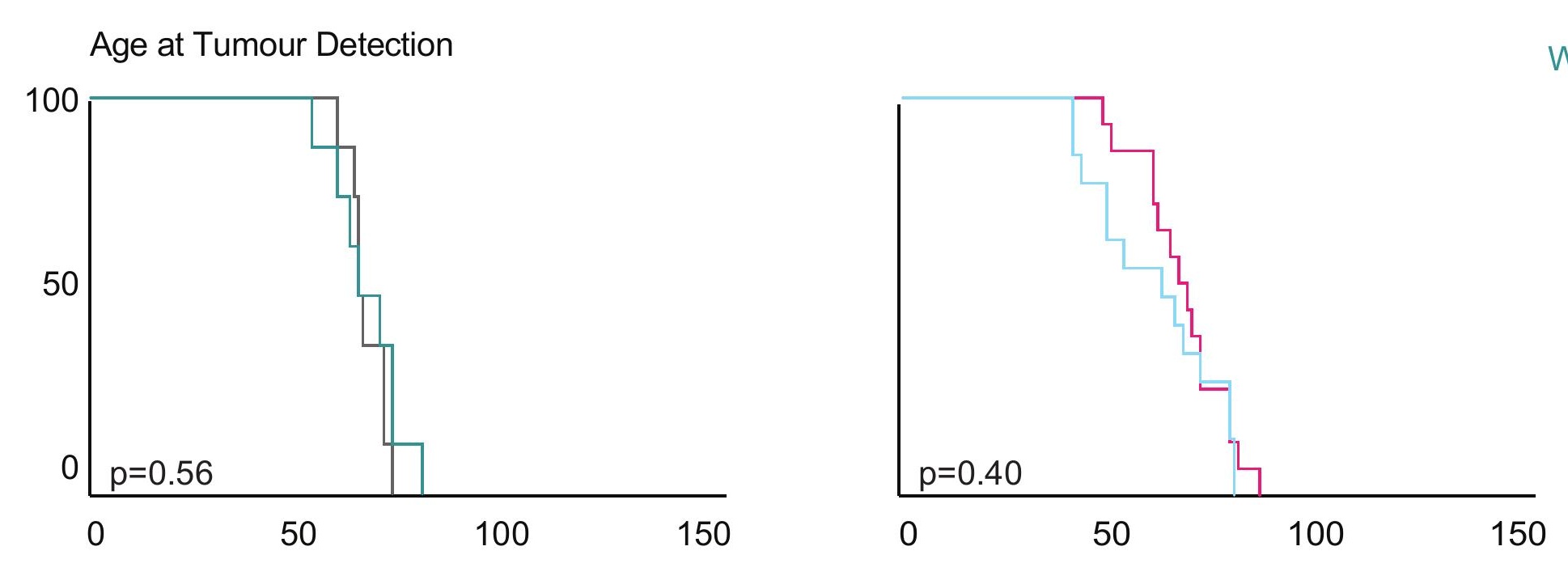

Time from detection to Ethical Endpoint

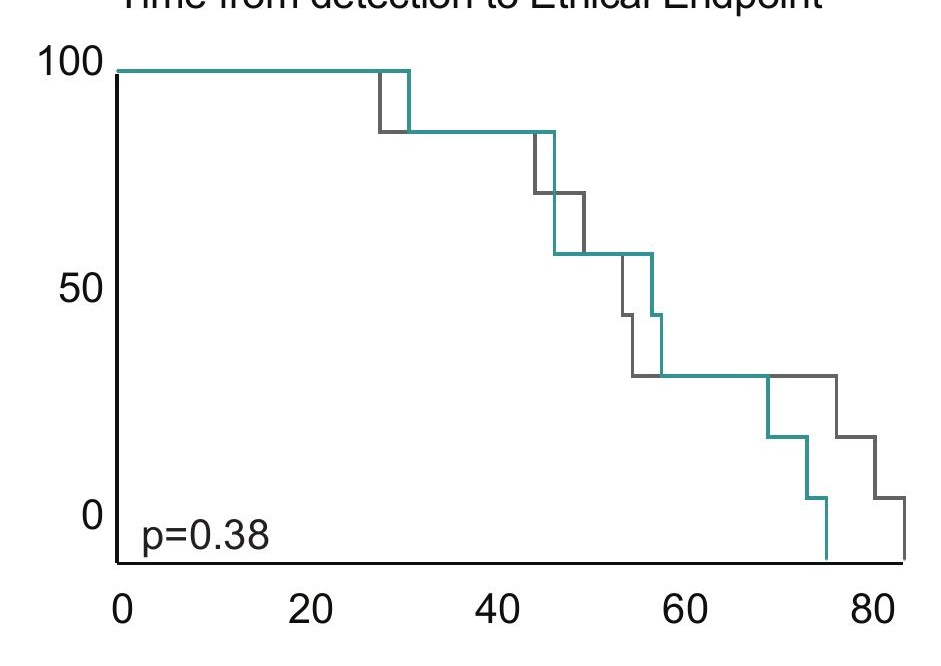

Age at Ethical Endpoint

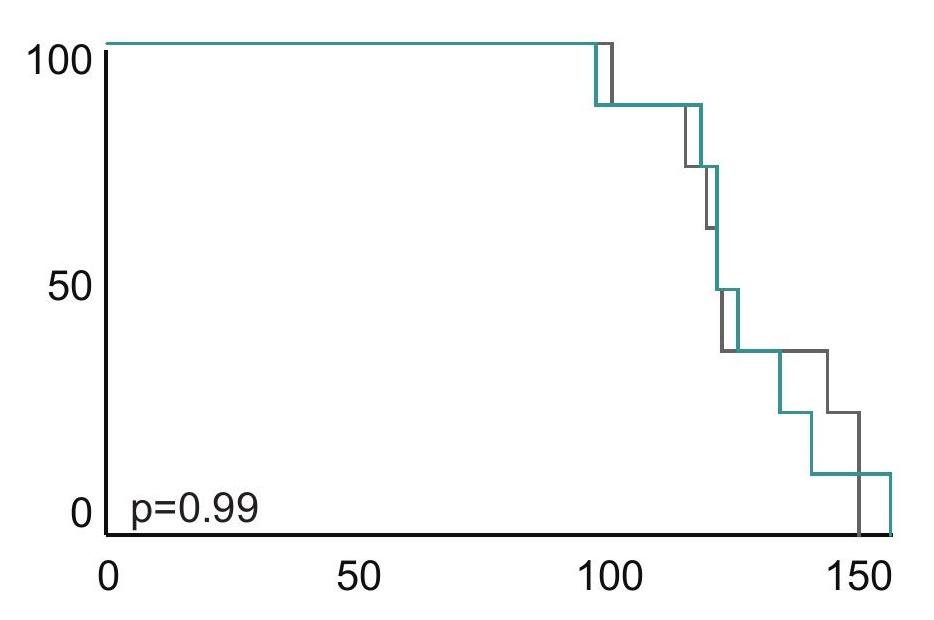

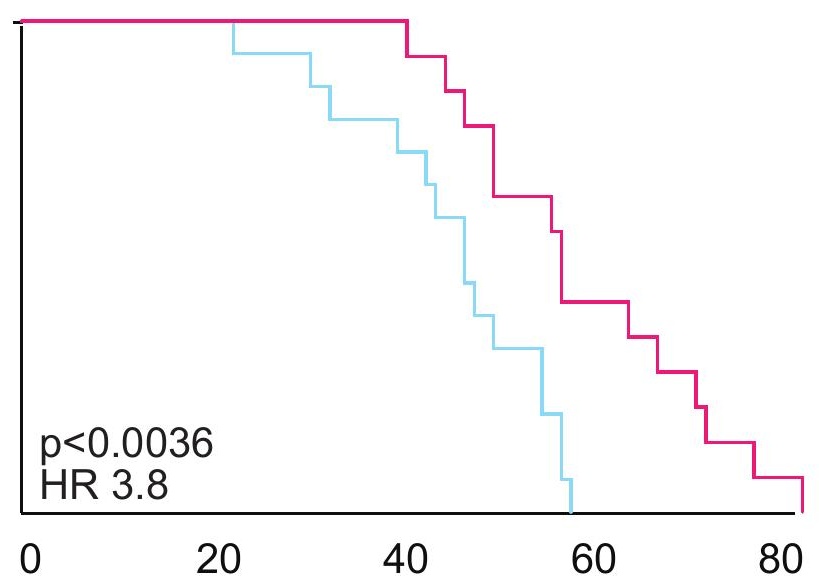
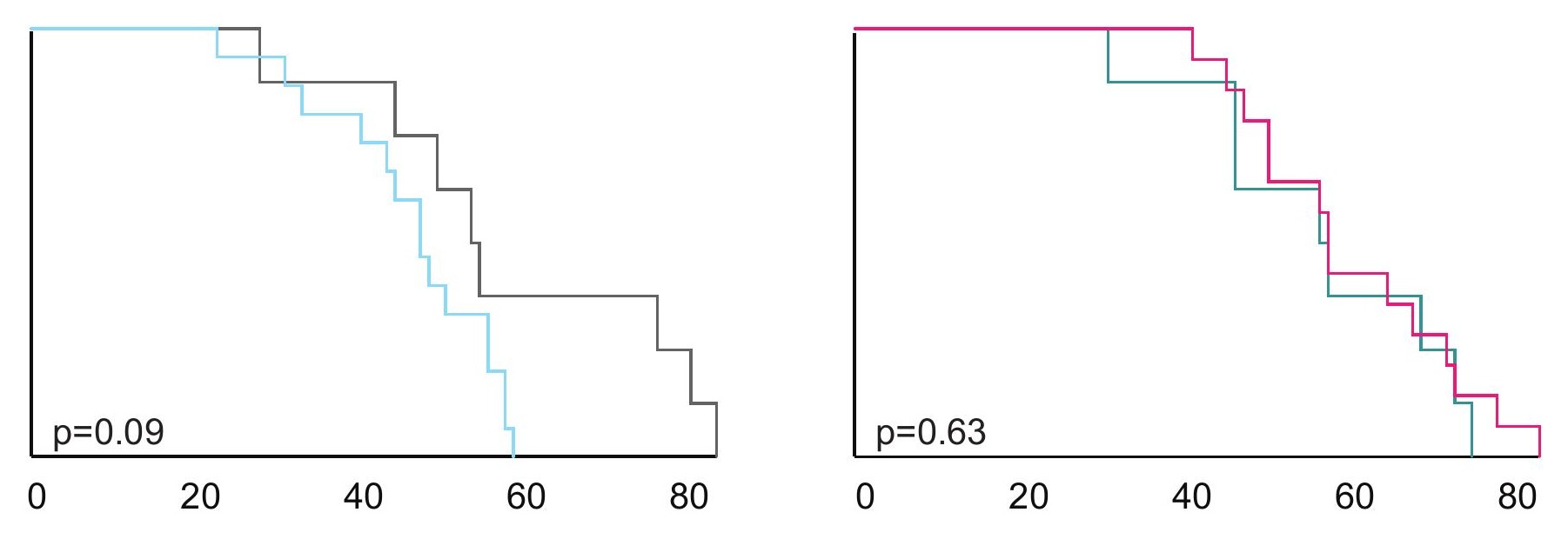

Days

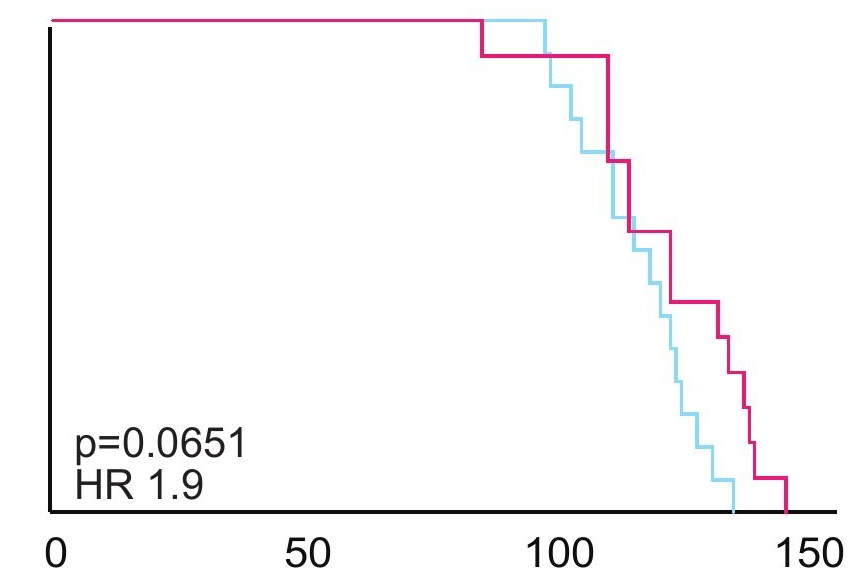

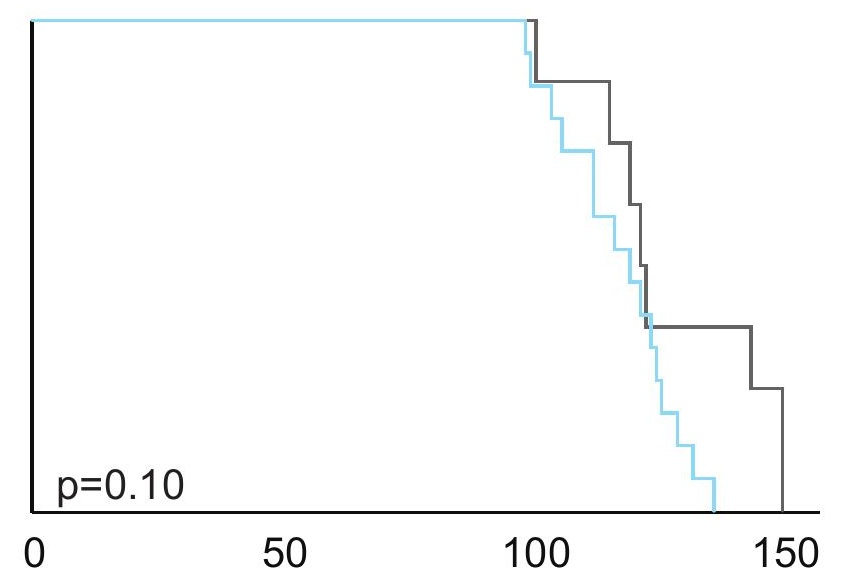

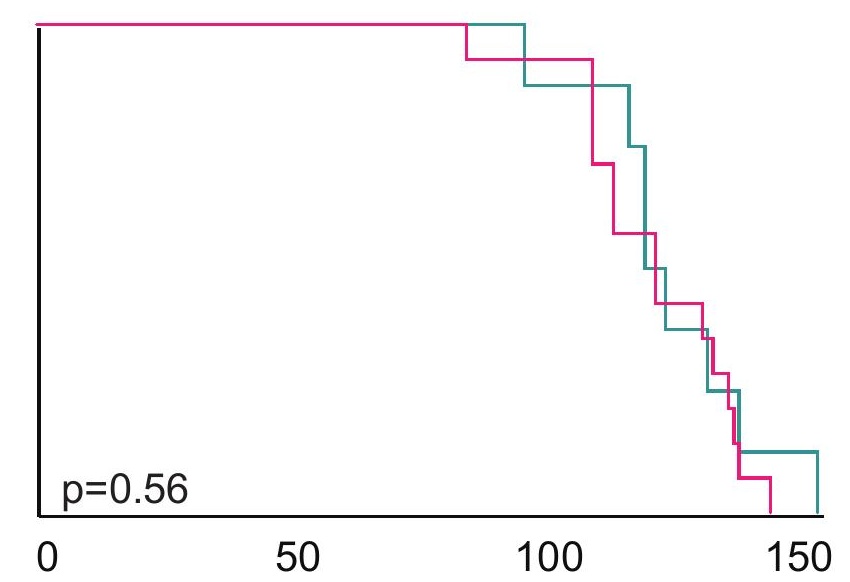

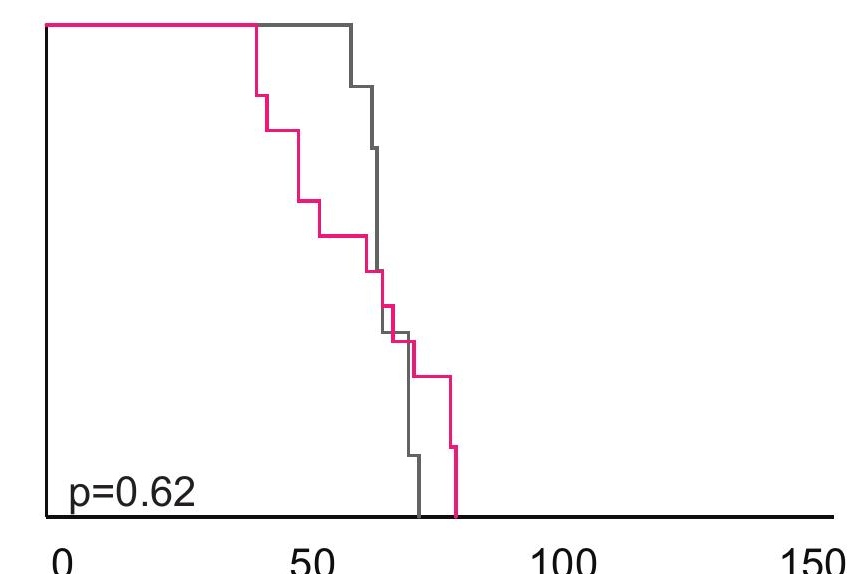
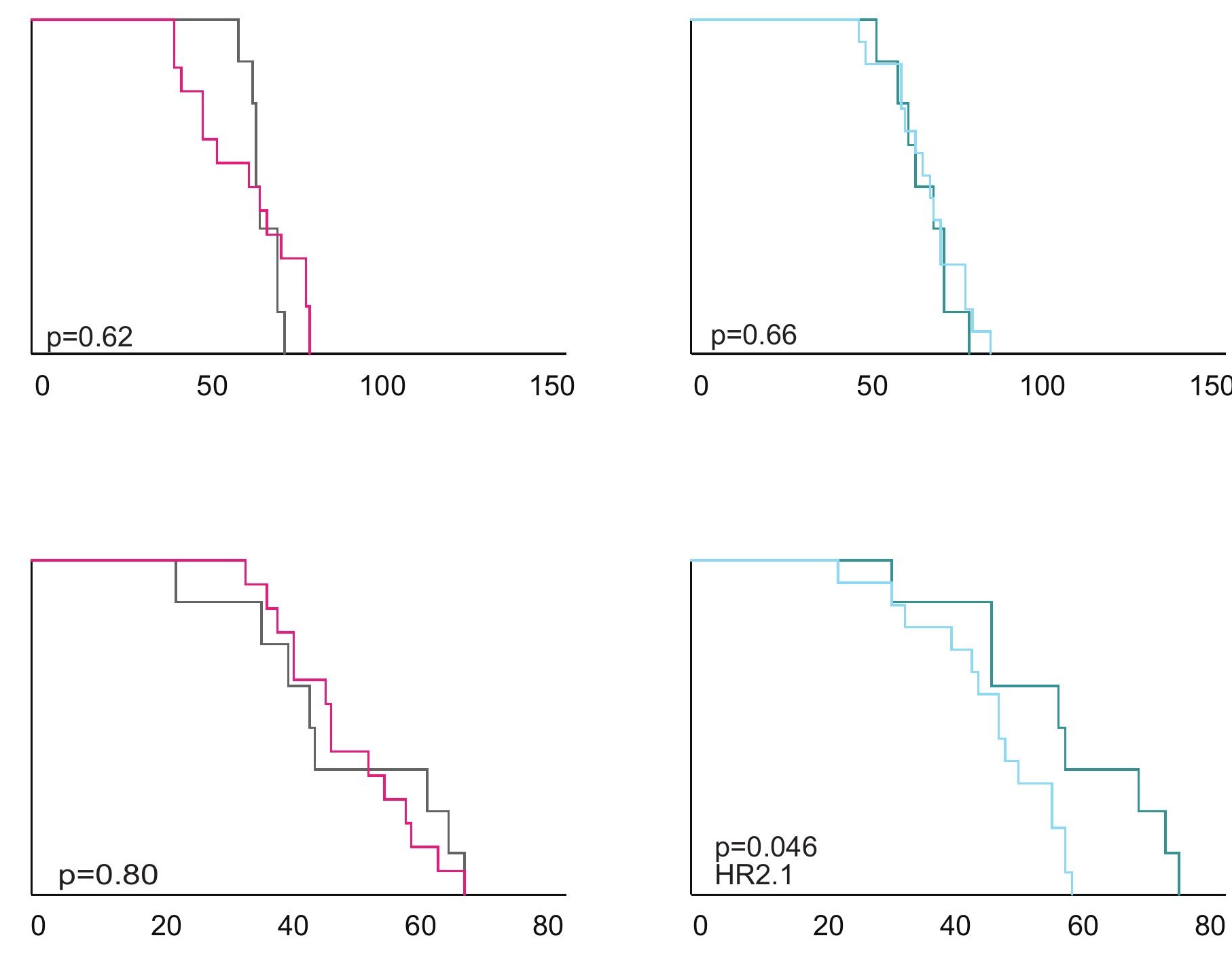

$\mathrm{p}=0.046$
$\mathrm{HR} 2.1$
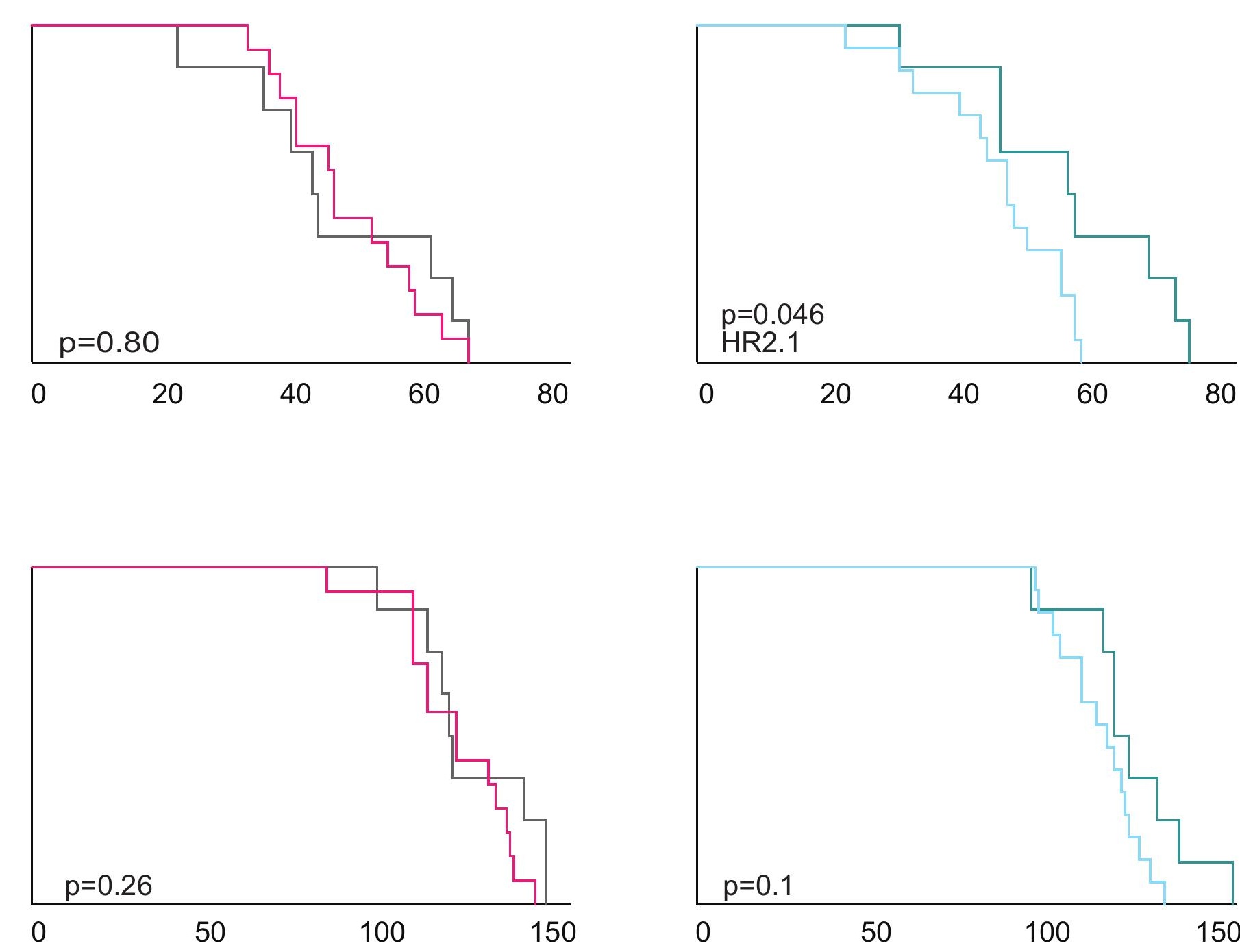